\title{
The acceleration of dissolved cobalt's ecological stoichiometry due to biological uptake, remineralization, and scavenging in the Atlantic Ocean
}

\author{
Mak A. Saito ${ }^{1}$, Abigail E. Noble ${ }^{1}$, Nicholas Hawco ${ }^{1}$, Benjamin S. Twining ${ }^{4}$, Daniel C. Ohnemus ${ }^{2}$, Seth G. John ${ }^{2}$, \\ Phoebe Lam ${ }^{1,3}$, Tim M. Conway ${ }^{5}, \operatorname{Rod}_{\text {Johnson }}{ }^{6}$, Dawn Moran $^{1}$, and Matthew McIlvin ${ }^{1}$ \\ ${ }^{1}$ Stanley W. Watson Biogeochemistry Laboratory, Marine Chemistry and Geochemistry Department, Woods Hole \\ Oceanographic Institution, Woods Hole, MA 02543, USA \\ ${ }^{2}$ University of Southern California, Department of Earth Sciences, Los Angeles, CA 90089, USA \\ ${ }^{3}$ Department of Ocean Sciences, University of California Santa Cruz, Santa Cruz, CA 95064, USA \\ ${ }^{4}$ Bigelow Laboratory for Ocean Sciences, East Boothbay, ME 04544, USA \\ ${ }^{5}$ College of Marine Sciences, University of South Florida, St. Petersburg, FL 33701, USA \\ ${ }^{6}$ Bermuda Institute of Ocean Sciences, St. Georges, Bermuda GE 01, UK \\ Correspondence to: Mak A. Saito (msaito@whoi.edu)
}

Received: 24 November 2016 - Discussion started: 29 November 2016

Revised: 1 August 2017 - Accepted: 28 August 2017 - Published: 20 October 2017

\begin{abstract}
The stoichiometry of biological components and their influence on dissolved distributions have long been of interest in the study of the oceans. Cobalt has the smallest oceanic inventory of inorganic micronutrients and hence is particularly vulnerable to influence by internal oceanic processes including euphotic zone uptake, remineralization, and scavenging. Here we observe not only large variations in $\mathrm{dCo}: \mathrm{P}$ stoichiometry but also the acceleration of those $\mathrm{dCo}: \mathrm{P}$ ratios in the upper water column in response to several environmental processes. The ecological stoichiometry of total dissolved cobalt (dCo) was examined using data from a US North Atlantic GEOTRACES transect and from a zonal South Atlantic GEOTRACES-compliant transect (GA03/3_e and GAc01) by Redfieldian analysis of its statistical relationships with the macronutrient phosphate. Trends in the dissolved cobalt to phosphate ( $\mathrm{dCo}: \mathrm{P})$ stoichiometric relationships were evident in the basin-scale vertical structure of cobalt, with positive $\mathrm{dCo}$ : $\mathrm{P}$ slopes in the euphotic zone and negative slopes found in the ocean interior and in coastal environments. The euphotic positive slopes were often found to accelerate towards the surface and this was interpreted as being due to the combined influence of depleted phosphate, phosphorus-sparing (conserving) mechanisms, increased alkaline phosphatase metalloenzyme production (a zinc or perhaps cobalt enzyme), and biochemical substitution of Co for
\end{abstract}

depleted Zn. Consistent with this, dissolved Zn (dZn) was found to be drawn down to only 2 -fold more than dCo, despite being more than 18 -fold more abundant in the ocean interior. Particulate cobalt concentrations increased in abundance from the base of the euphotic zone to become $\sim 10 \%$ of the overall cobalt inventory in the upper euphotic zone with high stoichiometric values of $\sim 400 \mu \mathrm{mol} \mathrm{Co} \mathrm{mol}^{-1} \mathrm{P}$. Metaproteomic results from the Bermuda Atlantic Timeseries Study (BATS) station found cyanobacterial isoforms of the alkaline phosphatase enzyme to be prevalent in the upper water column, as well as a sulfolipid biosynthesis protein indicative of $\mathrm{P}$ sparing. The negative $\mathrm{dCo}: \mathrm{P}$ relationships in the ocean interior became increasingly vertical with depth, and were consistent with the sum of scavenging and remineralization processes (as shown by their $\mathrm{dCo}: \mathrm{P}$ vector sums). Attenuation of the remineralization with depth resulted in the increasingly vertical $\mathrm{dCo}: \mathrm{P}$ relationships. Analysis of particulate Co with particulate $\mathrm{Mn}$ and particulate phosphate also showed positive linear relationships below the euphotic zone, consistent with the presence and increased relative influence of Mn oxide particles involved in scavenging. Visualization of $\mathrm{dCo}$ : P slopes across an ocean section revealed hotspots of scavenging and remineralization, such as at the hydrothermal vents and below the oxygen minimum zone (OMZ) region, respectively, while that of an estimate of $\mathrm{Co}^{*}$ illustrated sto- 
ichiometrically depleted values in the mesopelagic and deep ocean due to scavenging. This study provides insights into the coupling between the dissolved and particulate phase that ultimately creates Redfield stoichiometric ratios, demonstrating that the coupling is not an instantaneous process and is influenced by the element inventory and rate of exchange between phases. Cobalt's small water column inventory and the influence of external factors on its biotic stoichiometry can erode its limited inertia and result in an acceleration of the dissolved stoichiometry towards that of the particulate phase in the upper euphotic zone. As human use of cobalt grows exponentially with widespread adoption of lithium ion batteries, there is a potential to affect the limited biogeochemical inertia of cobalt and its resultant ecology in the oceanic euphotic zone.

\section{Introduction}

The study of the elemental composition of biological material has long been of great interest to environmental scientists. Redfield et al. pioneered the early observations that both dissolved and particulate phases of carbon, nitrogen, and phosphorus occurred in surprisingly fixed ratios in the sea, implying a connection between environmental distributions and biochemistry (Redfield, 1958; Redfield et al., 1963). More recently, studies have identified deviations from Redfield's elemental ratio (Martiny et al., 2013), as well as extended the biological stoichiometry to metal micronutrients in some microorganisms (Ho et al., 2003; Outten and O'Halloran, 2001; Sunda and Huntsman, 1995). Cobalt has the distinction of being both the scarcest of metal micronutrients in the oceans and of having perhaps the most variable of elemental stoichiometries in both dissolved and particulate phases (Saito et al., 2010; Noble et al., 2017). This paper aims to characterize cobalt's unusual behavior, both for the purpose of improving the knowledge of cobalt biogeochemistry and to further our general understanding of the processes that drive the connection between elemental environmental distributions and cellular biochemistries.

The biogeochemical cycle of cobalt is one of the more complex among trace metals present in the ocean. Complexities affecting cobalt include chemical processes such as redox transformations, complexation, low solubility and incorporation into mineral phases, and biological processes such as varying biochemical requirements and an early adoption of cobalt during Earth's biological and geochemical coevolution. The nutritional importance of cobalt stems from its requirement in the biosynthesis of vitamin $\mathrm{B}_{12}$ and subsequent requirements of the vitamin (Rodionov et al., 2003), as well as for its ability to substitute within a diatom carbonic anhydrase enzyme (Morel et al., 1994; Roberts et al., 1997). There are likely also other, as yet undetermined, biochemical functions of cobalt within both cyanobacteria that have an absolute requirement for cobalt (Saito et al., 2002), and other eukaryotic phytoplankton that often show a physiological capacity for substitution of cobalt for zinc (Saito and Goepfert, 2008; Sunda and Huntsman, 1995). These cobalt micronutritional requirements have been proposed to be important in the ecology of phytoplankton, such as the marine cyanobacteria Synechococcus, as well as the coccolithophore Emiliania huxleyi (Ahlgren et al., 2014; Sunda and Huntsman, 1995).

The confluence of these chemical and biological processes results in cobalt having a complex elemental cycle that has been described as a "hybrid type" of the nutrient and scavenged vertical profile categories (Bruland and Lohan, 2003; Noble et al., 2008). The utilization of cobalt as a nutrient by phytoplankton results in surface depletion as well as subsequent accumulation at intermediate depths through remineralization of sinking particulate material. In contrast, the scavenging process for cobalt is likely a one-way flux removing dissolved cobalt from seawater that results in depletion at intermediate and deep ocean depths, and is thought to be driven by the co-oxidation of cobalt upon microbial oxidation and precipitation of manganese oxide around small neutrally buoyant bacteria (Cowen and Bruland, 1985; Lee and Tebo, 1994; Moffett and Ho, 1996; Tebo et al., 1984). The factors that affect cobalt cycling, including its small oceanic inventory, susceptibility to scavenging, utilization dependence on the availability of other micronutrients, and labile concentrations present in the water column, make it uniquely exposed to multiple processes that can have a dramatic effect on the vertical and sectional structure of its oceanic distributions. As human use of cobalt grows exponentially with widespread adoption of lithium ion batteries, there is a potential to alter this dynamic biogeochemical cycling and ecology of cobalt in the oceanic euphotic zone. In particular, the South Atlantic, with its particularly scarce upper water column cobalt, is in close proximity to the Congo River, which is the watershed for the largest cobalt mines being built. Similarly, the extent of anthropogenically released cobalt from battery disposal is not well constrained and could contribute significant fluxes of cobalt to aquatic ecosystems in the future.

The microbial ocean ecosystem's nutrient stoichiometry has been inferred by examination of both the elemental composition of dissolved and particulate phases. This approach was first pioneered by Alfred Redfield for dissolved and particulate nitrogen and phosphate (Redfield, 1958; Redfield et al., 1963). As a micronutrient with a very small oceanic inventory, cobalt provides a unique case study for considering the stoichiometric coupling between dissolved and particulate phases. When applied to cobalt, linear relationships between dissolved cobalt and soluble reactive phosphate $(\mathrm{dCo}: \mathrm{P})$ can be interpreted as a time-integrated signal of the extent of cobalt utilization by the resident phytoplankton community and their subsequent remineralization from the biological particulate phase. The aggregate slope of 
this correlation is often described as "ecological stoichiometry" for its inferred biological usage across a diversity of organisms present (Sterner and Elser, 2002). An emerging feature and mystery regarding cobalt relative to other macro$(\mathrm{N}$ and $\mathrm{P})$ and micronutrients $(\mathrm{Zn}$ and $\mathrm{Cd}$ ) is its unusually large range in stoichiometries, spanning more than an order of magnitude from $29 \mu \mathrm{mol}: \mathrm{mol}$ in the central North Pacific to $560 \mu \mathrm{mol}: \mathrm{mol}$ in the equatorial Atlantic (Noble et al., 2012, 2008; Saito et al., 2010; Saito and Moffett, 2002). That high equatorial Atlantic value has long appeared to be an outlier, and these putative high stoichiometries are a focus of this study. The biochemical basis for this stoichiometric variability remains unknown.

Within the ocean interior, cobalt scavenging is frequently described as a critically important process for Co. But in actuality there has been little direct evidence provided to support this assertion. Some of the available datasets include several process studies of $\mathrm{Co}$ and $\mathrm{Mn}$ radiotracer uptake into biotic particles in the Sargasso Sea and coastal environments (Lee and Fisher, 1993; Moffett and Ho, 1996), a study of Co and Mn precipitation in anoxic fjords (Tebo et al., 1984), and laboratory experiments demonstrating that manganeseoxidizing bacteria also oxidize Co under aerobic conditions (Lee and Tebo, 1994). These few studies, combined with early observations of the depletion of dissolved cobalt in intermediate and deep waters (Knauer et al., 1982; Martin et al., 1989), and observations of a "cobalt curl" in the plots of dissolved cobalt and phosphate space showing preferential removal of Co vs. P (Noble et al., 2012; Saito et al., 2010), have contributed to this notion that scavenging is an important process. A recent study put forth a contrary argument that scavenging is less important in the cycling of dissolved cobalt, and that instead cobalt depletion in the ocean interior can be better explained by physical and remineralization processes (Dulaquais et al., 2014b).

Improved analytical methods for the determination of dissolved $\mathrm{Co}$, and the resulting recent production of large GEOTRACES datasets (Geotraces Group, 2015), provide new opportunities to explore the variability in Co stoichiometry and the processes that create this range (Baars and Croot, 2015; Bown et al., 2011, 2012; Dulaquais et al., 2014a, b; Hawco et al., 2016; Noble et al., 2012, 2008; Saito et al., 2010; Shelley et al., 2012). Here we examine and compare two zonal full depth sections of total dissolved cobalt and labile cobalt from the North and South Atlantic Ocean to examine the tug-ofwar among competing processes affecting cobalt cycling in the oceanic water column. Specifically, we have developed and employed a fine-scale Redfieldian statistical analysis of the variation in the stoichiometry of cobalt relative to phosphorus across vertical and horizontal dimensions to discern biogeochemical processes influencing dissolved cobalt in the Atlantic Ocean. This paper is a companion to that of Noble et al. (2017), describing the sources and distributions of dissolved cobalt and its chemical speciation in the US North Atlantic GEOTRACES GA03 section.

\section{Materials and methods}

\subsection{Data acquisition and sources}

Total dissolved cobalt and cobalt speciation data utilized in this analysis were obtained from the two legs of the US North Atlantic GA03 and GA03_e transect (2010 and 2011, also described as USGT10 and USGT11, respectively) and the GEOTRACES-compliant CoFeMUG GAc01 transect (Noble et al., 2012; Saito et al., 2013). All total dissolved cobalt and labile cobalt analyses (defined as with and without UV irradiation, respectively) were conducted using cathodic stripping voltammetry methods using dimethyl glyoxime as the added complexing agent, as described in the companion paper (Noble et al., 2017) and in Noble et al. (2012) for GAc01. Both datasets utilized GEOTRACES intercalibration standards to ensure the data are intercomparable (Noble et al., 2012, 2017).

\subsection{Statistical analysis of cobalt stoichiometry}

Two-way linear regressions of dissolved cobalt and phosphate were conducted on both datasets using a custom script written in MATLAB. This script called the external m-file lsqfitma.m, written by Ed Peltzer for two-way linear regressions, which are the preferred approach to analysis of stoichiometry because there is no assumption of dependence (parameter $x$ on $y$ or vice versa) between variables as exists in standard least squares linear regressions (Glover et al., 2011). Regressions were performed using two strategies: (1) on hand-selected depth ranges in the overall data by geographic region, and (2) on groups of five-point adjacent data points moving downward point by point within each vertical profile. The latter analyses were conducted within MATLAB scripts for the two-way linear regression analyses. Linear regression results used for figures were limited to those with correlation coefficient $(r)$ values greater than $|0.7|$, with $r>0.7$ corresponding to positive slopes and $<-0.7$ to negative slopes.

\subsection{Global metaproteomic analyses for relevant metalloenzymes}

Protein samples were collected from a Bermuda Atlantic Time-series Study (BATS) cruise (B313, April 2015) using in situ McLane pumps deployed with mini-MULVFS filter heads (Bishop et al., 2012), and size-fractionated as previously described using $0.2,3.0$, and $51 \mu \mathrm{m}$ filters (Saito et al., $2015,2014)$. The $0.2 \mu \mathrm{m}$ filter was extracted for total protein content of the microbial community using a SDS detergent and an adapted magnetic hydrophilic bead methodology (Hughes et al., 2014; Saito et al., 2014). The samples were analyzed by ultra-high-resolution mass spectrometry on a Thermo Fusion using TopN data-dependent acquisition mode and dynamic exclusion of $30 \mathrm{~s}$. Two alkaline phosphatases were identified from the global metaproteome 
datasets using a custom metagenomics and genomic dataset as previously described that contains numerous cyanobacterial genomes (HOTPSIG; Saito et al., 2015, 2014). The full discussion of this metaproteome dataset is beyond the scope of this paper and will be described in a subsequent paper. The sulfolipid (UDP-sulfoquinovose) biosynthesis protein identified corresponds to a sequence from the North Atlantic Prochlorococcus strain NATL2a (PMN2A_1264). The two alkaline The two alkaline phosphatase (PhoA) proteins identified corresponded to sequences from the genomes of two North Atlantic picocyanobacterial isolates, Prochlorococcus NATL1 (gene 11501) and Synechococcus WH8102 (gene SYNW2391).

\subsection{Complementary datasets: particulate metal and phosphorus datasets, dissolved $\mathrm{Zn}$ and $\mathrm{Cd}$, and macronutrients}

Several datasets from the US GA03/3_e 2010 and 2011 cruises (USGT10 and USGT11) North Atlantic Zonal Transect (NAZT) expedition were used to contribute to the interpretation of this study, including soluble reactive phosphate, particulate cobalt and phosphate, and dissolved zinc and cadmium. Particulate metal and phosphorus datasets were used for comparison to dissolved Co in this study. McLane pump small size fraction membrane filters (SSF, 0.8-51 $\mu \mathrm{m}$, Pall Supor polyethersulfone membrane filters) were utilized for full ocean depth comparisons, and membrane filters from Go-Flo bottles (Pall Supor polyethersulfone membrane filters, $0.2 \mu \mathrm{m}$ ) were used for higher-resolution upper water column comparisons. The data as well as methods for collection, digestion, and analyses were previously described (Ohnemus and Lam, 2015; Twining et al., 2015). Excess cobalt, defined here as the particulate cobalt beyond lithogenic contribution, was calculated using an upper continental crust $\mathrm{Co}: \mathrm{Al}$ ratio $\left(17544 \mathrm{~mol} \mathrm{~mol}^{-1}\right.$; Taylor and McLennan, 1985) to the equation $p$ Co_xs_SSF $=p$ Co_SSF $-57 \mu \mathrm{mol} \mathrm{mol}{ }^{-1} \times \mathrm{pAl} \_\mathrm{SSF}$ (where $p$ refers to particulate, xs excess, and SSF small size fraction). In this usage, excess cobalt encompasses the biological and authigenic contributions to particulate cobalt. Methods for the dissolved zinc and cadmium measurements using isotope dilution on a multicollector ICP-MS were described in Conway et al. (2013), and the data were described in related North Atlantic papers (Conway and John, 2014, 2015). Soluble reactive phosphorus was measured by nutrient auto-analyzer as described previously for the South Atlantic (Noble et al., 2012), and by the Scripps ODF facility for the North Atlantic with a detection limit of $0.02 \mu \mathrm{M}$ (S. Becker, personal communication, 2017).

\section{Results and discussion}

\subsection{Statistical analysis of $\mathrm{dCo}: \mathrm{P}$ distributions in the North and South Atlantic Ocean}

The study of nutrient stoichiometry has a long and important tradition in oceanography. For example, when nitrogen and cadmium concentrations have been compared relative to those of phosphorus, their linear relationships have been interpreted to imply an ecological use of those nutrients throughout the microbial and phytoplankton community through their uptake and release from the biological particulate phase (Boyle et al., 1976; Redfield et al., 1963; Sunda and Huntsman, 2000), leading to the discovery of new metalloenzymes and the development of paleoceanographic proxies (Boyle, 1988; Lane et al., 2005). The slopes of these relationships have been used to infer the ecological stoichiometries of the biological processes that created them, based on the underlying idea that movement of elements between the dissolved and biological particulate phases results in a "biochemical circulation" of the oceans that is both distinct from and yet also overlaid upon the physical ocean circulation processes (Redfield et al., 1963). Deviations in the stoichiometry of N:P inorganic chemical species (nitrate and soluble reactive phosphate) in the environment have been described as evidence for non-Redfieldian stoichiometry (Anderson and Pondaven, 2003; Arrigo et al., 1999). Similarly, "kinks" in the dissolved $\mathrm{Cd}$ : phosphate relationships have been suggested to result from specific regional biogeochemical processes such as iron limitation, competition of ferrous iron at the cadmium transporter site, and variations in Zn availability (Cullen et al., 2003; Lane et al., 2009; Sunda and Huntsman, 2000). For cobalt, there is an emerging picture that its ecological stoichiometry is particularly complex, with larger ecological stoichiometric variations compared to $\mathrm{N}$ and even trace elements such as $\mathrm{Cd}$. Yet, as previously suggested (Sunda and Huntsman, 1995), these Co : P signals likely provide important information regarding the biological and chemical processes influencing dissolved cobalt distributions. One of the outstanding questions regarding dissolved stoichiometries of metals and nutrients is the nature and strength of their connection to the particulate phase.

In this study, total dissolved and labile datasets from the US North Atlantic GEOTRACES Transect (GA03 and GA03_e) and the South Atlantic GEOTRACES-compliant CoFeMUG expedition (GAc01; Fig. 1) were analyzed for their relationships relative to the macronutrient phosphate. These large Atlantic datasets provided an opportunity to examine Co biogeochemical complexity and to test prior hypotheses regarding micronutrition and element substitution. Simple two-way linear regressions were employed in two manners for the examination of the ecological stoichiometry of dissolved cobalt and phosphate $\left(\mathrm{dCo}: \mathrm{PO}_{4}^{3-}\right.$, or $\mathrm{dCo}: \mathrm{P}$ from here on; see "Materials and methods" for specific details). The first approach ("aggregate regression" analysis 


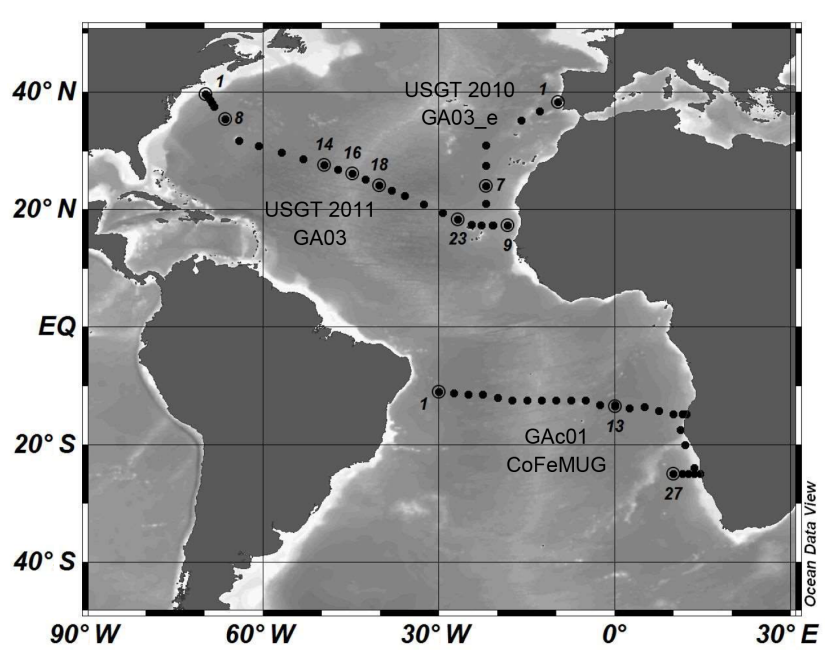

Figure 1. Expedition tracks of the US North Atlantic GEOTRACES zonal transect (GA03/3_e; USGT10; cruise number KN199-4, stations 1-12; and USGT11, KN199-5b stations 1-24) and the GEOTRACES-compliant CoFeMUG South Atlantic Expedition (GAc01; KN192-5, 2007). Stations were numbered sequentially from the beginning of each expedition (Portugal for GA03_e; Woods Hole for GA03, USA; and Natal, Brazil, for GAc01, respectively) with station numbers shown for selected stations. The North Atlantic stations are described in later figures by the year and station number (e.g., 11-01 for the 2011 expedition).

from here on), resembled a standard Redfieldian analysis that determined dissolved cobalt versus phosphate relationships within specific water parcels (subsets of the sections) with some selected data points removed that were associated with proximity to coastal and hydrothermal regions. The resulting $\mathrm{dCo}$ and phosphate distributions were visualized with respect to the origin of their water masses (Fig. 2).

The second approach ("profile-based regression" approach from here on) involved an unbiased and inclusive statistical analysis also using linear regressions, but now applied to a moving five-point depth window on each individual vertical profile in order to capture fine-scale structural changes in Co ecological stoichiometry (Fig. 3). Because the processes of remineralization of sinking biomass and scavenging onto particles result in vertical transport through the water column, this profile-based regression statistical analysis could be well suited to detecting changes in stoichiometry of dissolved metals relative to phosphate, and how those processes and their vertical signals are gradually integrated across horizontally advected isopycnal surfaces. Notably, positive dCo: P (Fig. 3b and g) and negative dCo:P (Fig. 3c and h) slopes were identified in both basins, implying trends where dissolved Co and phosphate both increased, or dissolved Co decreased while phosphate increased, respectively. These trends increased in magnitude towards the surface and deep, respectively, as shown by visualizing variation in $\mathrm{dCo}: \mathrm{P}$ slope with depth (Fig. 3d and i), after filtering by correlation coefficients $(r)$ values above the $|0.7|$ threshold (equivalent to an $r^{2} \geq 0.49$ ), and data below this threshold were excluded (Fig. $3 e$ and j). A simple schematic of the influence of phytoplankton uptake, remineralization, scavenging and dust input is shown in Fig. 4g for comparison as well as actual measured vectors in Fig. 4a and d, where each dCo: P slope was represented as a vector in $\mathrm{dCo}$ and $\mathrm{P}$ space (vector lengths made uniform) and with a broad distribution range of $\mathrm{dCo}: \mathrm{P}$ slopes (Fig. 4b and e), and an explanation for these observed negative slopes is presented later in the paper (Sect. 3.3). Note that the depth associated with each linear regression result was assigned to the middle depth of the five depths being analyzed, resulting in no regression results data at the upper and lower two depths of each profile. Results of $\mathrm{dCo}: \mathrm{P}$ linear regression for individual vertical profiles are shown in Fig. 5 (sign of slope by color overlaid on dCo abundances) and 6 (magnitude of slope) to allow geospatial inspection and comparisons. Interpretations of these trends and their variability in slopes measured by both aggregate and profile regressions is discussed in the context of euphotic zone phytoplankton processes and mesopelagic scavenging processes in the subsequent sections.

\subsection{Ecological stoichiometry of cobalt across transects of the upper Atlantic Ocean}

\subsubsection{Distinct $\mathrm{dCo}: \mathrm{P}$ relationships in mid-euphotic to upper mesopelagic}

The aggregate regression analysis of the two zonal Atlantic Ocean sections found coherent large-scale linear relationships between dCo and phosphate in the mid-euphotic/upper mesopelagic. Distinct dCo: P stoichiometries were identified ranging from $31-67 \mu \mathrm{mol} \mathrm{mol}^{-1}$ ( $r^{2}$ of 0.71 to 0.93 ) in this mid-euphotic/upper mesopelagic, comparable to those observed in other geographic regions (Table 1). The Atlantic data were grouped into five broad regions: the eastern North Atlantic (USGT10-02 to USGT10-06), the North Atlantic Subtropical Gyre (USGT11-10 to USGT11-23), the Mauritanian Upwelling (USGT10-07 to USGT10-12 and USGT1124), the South Atlantic Subtropical Gyre (CoFeMUG Station 1-7), and the Angola Gyre/Benguela Upwelling (CoFeMUG stations 8-17; for individual regression plots see Noble et al., 2017, their Fig. 11). There were several observations of note. First, the highest dCo : P value, $67 \mu \mathrm{mol} \mathrm{mol}^{-1}$ $\left(r^{2}=0.93\right)$ observed between 135 and $400 \mathrm{~m}$ depth, was observed in the North Atlantic Subtropical Gyre, where phosphate concentrations were extremely low (often $<0.01 \mu \mathrm{M}$ within the euphotic zone below $100 \mathrm{~m}$ ). This value was similar to that reported by Dulaquais et al. (2014b) of $64 \mu \mathrm{M}: \mathrm{M}$. Second, the eastern North Atlantic (USGT10 stations 2-6) had a particularly deep range where the $\mathrm{dCo}: \mathrm{P}$ relationship was maintained (50-900 m, $41 \mu \mathrm{mol} \mathrm{mol}^{-1}, r^{2}=0.92$ ), likely indicating the pronounced influence of remineralization processes. This feature spans three water masses: North 
(a)

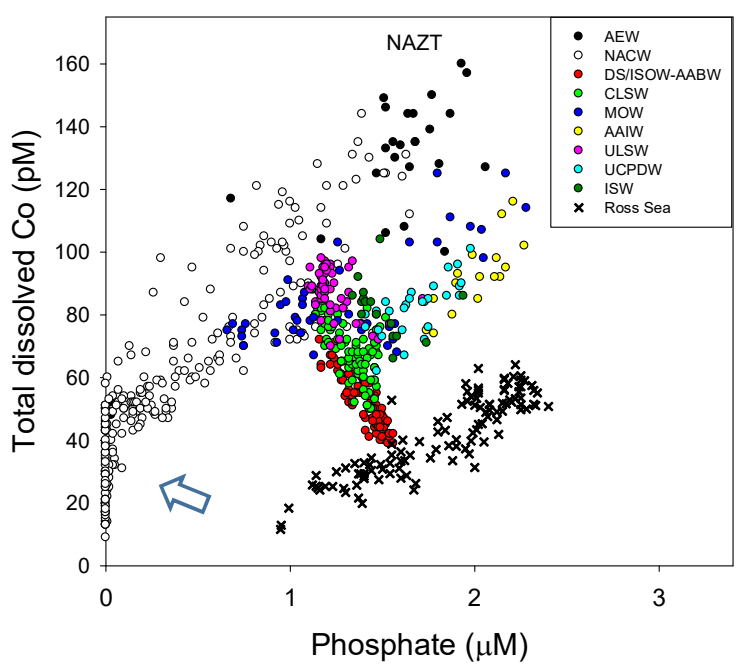

(b)

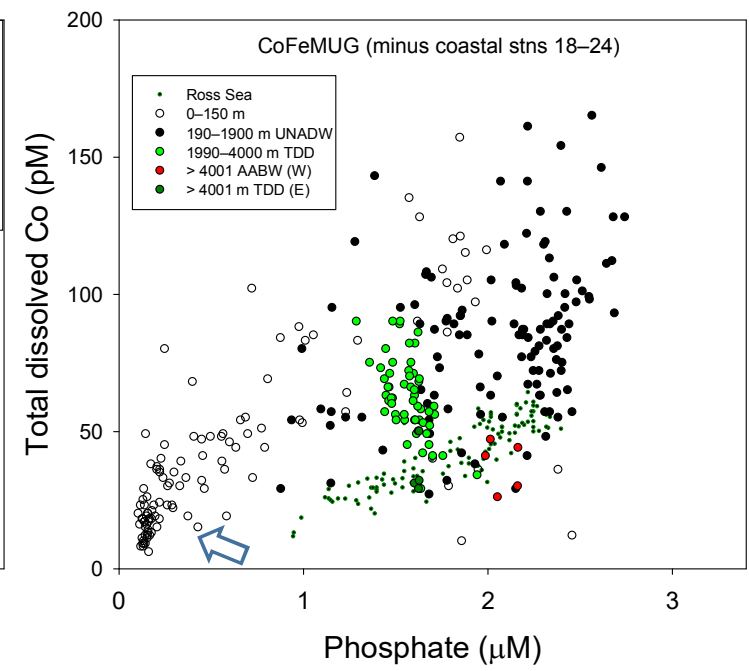

Figure 2. Total dissolved cobalt versus phosphate distributions observed across different regions in the North (GA03/3_e) and South Atlantic (GAc01; a and b, respectively). Water masses were identified by OMPA analysis (optimum multiparameter water mass analysis; DSOW Denmark Strait Overflow Water; ISOW - Iceland Scotland Overflow Water; CLSW - classical Labrador Sea Water; MOW - Mediterranean Overflow Water; ULSW - Upper Labrador Sea Water; UCDW - Upper Circumpolar Deep Water; AAIW - Antarctic Intermediate Water; ISW - Irminger Sea Water; Jenkins et al., 2015, their Table 1). In the South Atlantic water masses correspond broadly to water masses as described in Saito et al. (2012), where UNADW < $2000 \mathrm{~m}$ (Upper North Atlantic Deep Water), AABW > 4000 in the western basin, and TDD (two-degree discontinuity) was the major contributor to both 2000-4000 and $>4000 \mathrm{~m}$ in the eastern basin of the South Atlantic. Ross Sea dissolved cobalt data are included from Saito et al. (2010), representing a Southern Ocean endmember. Blue arrows indicate areas with steep $\mathrm{dCo}$ : P relationships.

Atlantic Central Water, Atlantic Equatorial Water, and even Mediterranean Outflow Water (the latter at $600-800 \mathrm{~m}$ for USGT10-2), and hence this $\mathrm{dCo}: \mathrm{P}$ coherence could be due to a regionally strong vertical influence from remineralization on the mesopelagic. Third, the region near and within the productive Mauritanian Upwelling, with their contributions from Atlantic Equatorial Waters (AEW) between 100 and $600 \mathrm{~m}$ depth (Jenkins et al., 2015), an oxygen minimum centered around $400 \mathrm{~m}\left(40-110 \mu \mathrm{mol} \mathrm{kg}{ }^{-1} \mathrm{O}_{2}\right)$, and atmospheric deposition from the Sahara, had a dissolved stoichiometry of $48 \mu \mathrm{mol} \mathrm{mol}^{-1}\left(r^{2}=0.83\right)$. Finally, linear regressions of aggregated data from the upper euphotic zone had low coefficients of determination $\left(r^{2}\right)$ and inspired the development of the profile-based methods described below.

These $\mathrm{dCo}: \mathrm{P}$ stoichiometries described above for the upper water column were likely controlled by the aggregate influences of phytoplankton uptake and remineralization on dissolved cobalt throughout this region, and their variability demonstrates how the influence of biological processes on cobalt inventories is dynamic. For example, the tightest correlation and steepest slope were found in the North Atlantic Subtropical Gyre (Table 1), excluding the profilebased analyses and the surface transect of the equatorial Atlantic (Saito and Moffett, 2002). These North Atlantic sites occurred where labile cobalt concentrations were high and a strong correlation between labile cobalt and phosphate was also observed ( $23 \mu \mathrm{mol} \mathrm{mol}{ }^{-1}, r^{2}=0.83$; Noble et al., 2017). The presence of a substantial labile cobalt pool was consistent with the observed high cobalt usage, since labile cobalt is likely highly bioavailable relative to complexed cobalt, particularly for eukaryotic phytoplankton, due to its ability to be taken up through divalent cation transporters (Saito et al., 2002, 2005).

The South Atlantic zonal section had an ecological stoichiometry in the mid-euphotic/upper mesopelagic zone $\left(31 \mu \mathrm{mol} \mathrm{mol}^{-1}, r^{2}=0.71,70-200 \mathrm{~m}\right)$ that was less than half that observed in the North Atlantic Subtropical Gyre $\left(67 \mu \mathrm{mol} \mathrm{mol}^{-1}\right.$; Table 1). The upper water column of the South Atlantic Subtropical Gyre was characterized by strong complexation of cobalt and higher phosphate throughout much of the region (Noble et al., 2017), both of which are consistent with a lower biological use of $\mathrm{Co}$, higher $\mathrm{P}$ use, and resultant lower $\mathrm{dCo}: \mathrm{P}$ stoichiometry. While the Mauritanian Upwelling region also showed evidence of a curve in the $\mathrm{dCo}: \mathrm{P}$ relationship that shifts to a deeper ecological stoichiometry of $47 \mu \mathrm{mol} \mathrm{mol}^{-1}\left(50-425 \mathrm{~m}, r^{2}=0.83\right)$, the Angola Gyre/Benguela Upwelling region did not demonstrate changes in ecological stoichiometry with depth and the aggregate $\mathrm{Co}: \mathrm{PO}_{4}^{3-}$ ratio observed was $48 \mu \mathrm{mol} \mathrm{mol}^{-1}(0$ $400 \mathrm{~m}, r^{2}=0.84$, Fig. 2). A potentially larger coastal sedimentary Co flux and entrainment in the phytoplankton uptake and remineralization likely contributes to this higher ratio as 
(a)

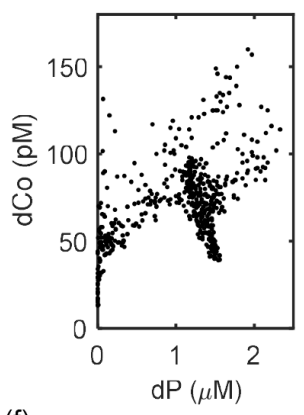

(f)

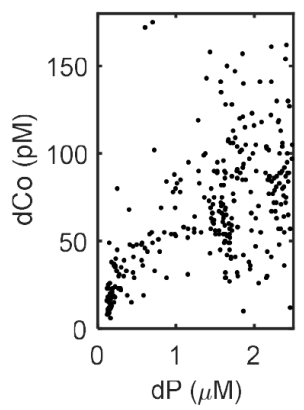

(b)

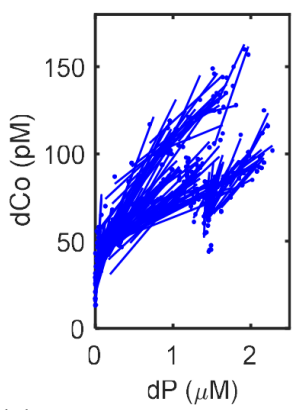

(g)

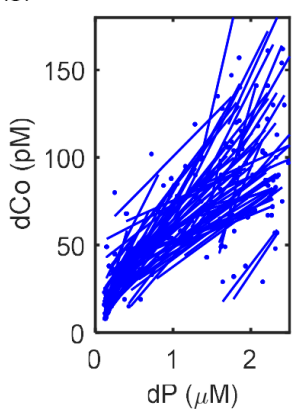

(c)

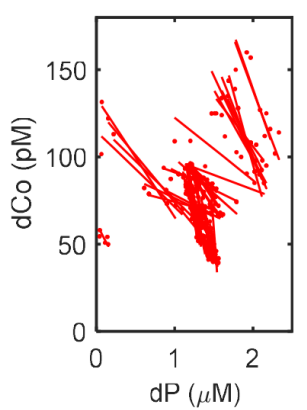

(h)

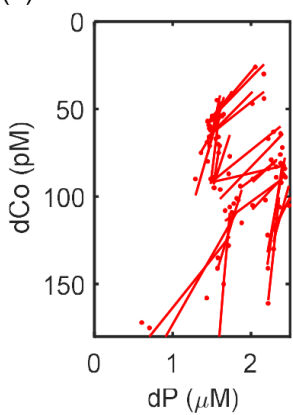

(d)

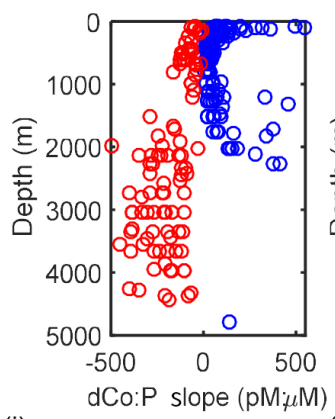

(i)

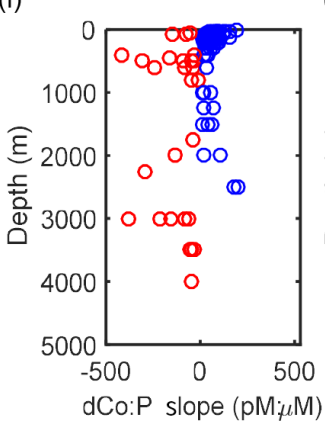

(e)

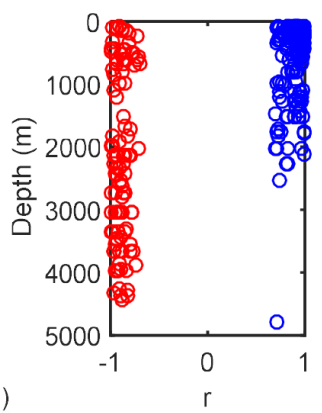

(j)

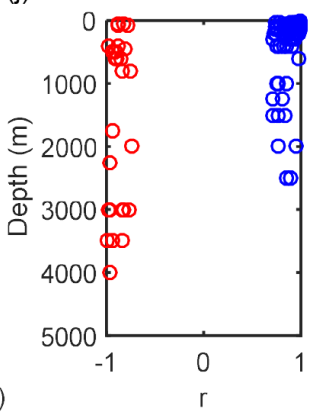

Figure 3. Five point moving window linear regression analyses of dissolved cobalt versus phosphate space. All data (a) and analyses (be) from the North Atlantic GA03/3_e section. All data (f) and analyses (g-j) from the South Atlantic GAc01 zonal section. (b, g) Data with a positive slope and $r$ values greater than 0.7 , after applying linear regressions on groups of five vertically adjacent data points within each profile across the entire transect. Solid blue lines represent the linear regressions superimposed on the data points analyzed. (c, $\mathbf{h}$ ) Data with a negative slope and $r$ values less than -0.7 , after applying linear regressions on groups of five vertically adjacent data points within each profile across the entire transect. Solid red lines represent the linear regressions superimposed on the data points analyzed. (d, i) Linear regression slopes versus depth for the five-point groupings; blue and red symbols represent positive and negative slopes, respectively. (e, j) $r$ values $(>|0.7|)$ used in the analyses relative versus depth.

a result of the lower oxygen waters sampled in the Benguela Upwelling (Noble et al., 2012). Consistent with this sampling of lower oxygen waters, the Benguela Upwelling region exhibits the highest total cobalt concentrations, yet labile cobalt is low, resulting in lower Co:P stoichiometry and a weaker statistical relationship $\left(r^{2}=0.84\right)$ than in the North Atlantic Subtropical Gyre as described in Noble et al. (2017).

\subsubsection{Evidence for elevated ecological stoichiometries of cobalt in the upper photic zone}

The aggregate $\mathrm{dCo}: \mathrm{P}$ relationships in the mid-photic zone and upper mesopelagic described above excluded shallower and deeper depths that deviated from the linear relationships. Closer examination revealed steeper coherent cobaltphosphate relationships that do not appear to be random phenomena. These deviations were observed above and below the selected mid-euphotic to upper mesopelagic depth range studied above, and appeared to be caused by distinct biological and scavenging processes, respectively. Specifically, these Atlantic datasets both showed the presence of an intriguing convex kink and near-vertical cloud of cobalt data points near the $x$ axis as phosphate became increas- ingly depleted (Fig. 2, blue arrows). While we have noticed these steep relationships previously (Saito et al., 2002; Noble et al., 2012), dCo:P relationships at shallower depths were often statistically insignificant when analyzed as part of a larger aggregated dataset as conducted in the previous section. The profile-based regressions applied to the $\mathrm{dCo}: \mathrm{P}$ dataset provided an effective alternative means to characterize these steep features. Numerous positive relationships with steep slopes were observed in the dCo-phosphate space (Fig. 3b, g), particularly in close proximity to the surface in both the North and South Atlantic basins as shown in $\mathrm{dCo}: \mathrm{P}$ slopes of individual profiles (Figs. 5 and 6). These dCo:P slopes when presented in vector form revealed a surprising extent of diversity with both positive and negative slopes (Fig. 4a, d). Moreover, the frequency of $\mathrm{dCo}: \mathrm{P}$ slope stoichiometries in histogram form was highest between 0 and $125 \mu \mathrm{mol}: \mathrm{mol}$ and decreased successively in the next three increasing bins of $125 \mu \mathrm{mol}: \mathrm{mol}$ in both the North and South Atlantic. From this histogram it is apparent there was a broad tail of $\mathrm{dCo}: \mathrm{P}$ slope stoichiometries spanning from $\sim 500$ to $-500 \mu \mathrm{mol}$ : mol.

In an effort to understand the processes causing the variability in $\mathrm{dCo}: \mathrm{P}$ slopes generated by the profile-regression 
Table 1. Ecological stoichiometries for dissolved cobalt, labile cobalt, and phosphate in the Atlantic Ocean and prior studies. LCo refers to labile cobalt; all other values are total dissolved cobalt (dCo). n.d.: not detected; $n$ : number of observations used.

\begin{tabular}{|c|c|c|c|c|c|c|}
\hline Geographic location & Study & $\begin{array}{r}\text { Depth } \\
(\mathrm{m})\end{array}$ & $\begin{array}{r}\text { Co } \\
(\mathrm{pM})\end{array}$ & $\begin{array}{r}\Delta \mathrm{Co}: \Delta \mathrm{P} \\
\left(\mu \mathrm{mol} \mathrm{mol}^{-1}\right)\end{array}$ & $r^{2}$ & $n$ \\
\hline North Atlantic aggregate LCo & this study & $48-300$ & n.d. -48 & 23 & 0.82 & 156 \\
\hline South Atlantic aggregate LCo & this study/Noble et al. (2012) & $48-300$ & n.d. -39 & 7 & 0.25 & 71 \\
\hline North Atlantic aggregate TCo & this study & $48-300$ & $9-150$ & 64 & 0.89 & 156 \\
\hline South Atlantic aggregate TCo & this study/Noble et al. (2012) & $48-300$ & $11-161$ & 53 & 0.83 & 76 \\
\hline Eastern North Atlantic & this study & $90-900$ & 34-94 & 41 & 0.92 & 41 \\
\hline Mauritanian Upwelling & this study & $48-425$ & $26-157$ & 48 & 0.83 & 53 \\
\hline North Atlantic Subtropical Gyre & this study & $135-400$ & $31-144$ & 67 & 0.93 & 68 \\
\hline South Atlantic Subtropical Gyre & this study/Noble et al. (2012) & $70-200$ & $13-58$ & 31 & 0.71 & 28 \\
\hline Angola Gyre & this study/Noble et al. (2012) & $0-400$ & $12-165$ & 48 & 0.79 & 59 \\
\hline North Atlantic Station 14 (2011) & this study; profile analysis & $40-136$ & $17-45$ & 320 & 0.71 & 5 \\
\hline North Atlantic Station 16 (2011) & this study; profile analysis & $40-136$ & $16-40$ & 544 & 0.79 & 5 \\
\hline North Atlantic Station 18 (2011) & this study; profile analysis & $40-137$ & $13-38$ & 491 & 0.51 & 5 \\
\hline North Atlantic Station 20 (2011) & this study; profile analysis & $40-137$ & $13-44$ & 197 & 0.67 & 5 \\
\hline Atlantic Meridonial TCo & Dulaquais et al. (2014b) & $0-250$ & $\sim 15-85$ & 23 & 0.53 & 228 \\
\hline North Atlantic Subtropical Gyre & Dulaquais et al. (2014b) & $0-250$ & $\sim 20-55$ & 66 & 0.65 & 32 \\
\hline South Atlantic Subtropical Gyre & Dulaquais et al. (2014b) & $0-250$ & $\sim 15-65$ & 53 & 0.7 & 51 \\
\hline Equatorial Atlantic & Dulaquais et al. (2014b) & $0-250$ & $\sim 20-85$ & 27 & 0.87 & 51 \\
\hline Subantarctic Waters (Atlantic) & Dulaquais et al. (2014b) & $0-250$ & $\sim 20-65$ & 22 & 0.79 & 22 \\
\hline NE Pacific (T5) & Martin et al. (1989) & $50-150$ & $8-32$ & 40 & 0.98 & 3 \\
\hline NE Pacific (T6) & Martin et al. (1989) & $50-150$ & $28-40$ & 36 & 0.99 & 3 \\
\hline NE Pacific (T8) & Martin et al. (1989) & $8-50$ & $25-55$ & 38 & 0.97 & 3 \\
\hline Equatorial Atlantic & Saito and Moffett (2002) & 5 & $5-87$ & 560 & 0.63 & 14 \\
\hline Peru Upwelling & Saito et al. (2004) & 8 & $21-315$ & 275 & 0.96 & 11 \\
\hline Ross Sea, Antarctica & Saito et al. (2010) & $5-500$ & $19-71$ & 38 & 0.87 & 164 \\
\hline Subtropical Pacific (Hawaii) & Noble et al. (2008) & $0-300$ & $3-52$ & 29 & 0.63 & 33 \\
\hline Subtropical Pacific (Hawaii) & Noble and Saito et al. (2008) & $0-250$ & $11-47$ & 37 & 0.91 & 19 \\
\hline Southern Ocean (S1) & Bown et al. (2011) & $20-100$ & $24-44$ & 49 & 0.91 & 5 \\
\hline Southern Ocean (S2) & Bown et al. (2011) & $15-120$ & $7-26$ & 44 & 0.99 & 5 \\
\hline Southern Ocean (L4) & Bown et al. (2011) & $30-150$ & $27-48$ & 48 & 0.87 & 4 \\
\hline
\end{tabular}

analysis, we focused on oligotrophic stations in the North Atlantic Subtropical Gyre, where these effects were particularly pronounced (USGT-2011 stations 14, 16, 18, and 20). Phosphate abundances were particularly depleted in this region (Fig. 7a), and the shallowest $\mathrm{dCo}: \mathrm{P}$ stoichiometries measured by the profile-based analysis were $320,544,491$, and $197 \mu \mathrm{mol} \mathrm{mol}^{-1}$ (Fig. 7d, centering around depths of 101, 92, 76 , and $76 \mathrm{~m}$, Table 1 ). These values were roughly an order of magnitude higher than the aggregate mid-euphotic upper mesopelagic zone values reported in the previous section and observed in other studies (Table 1). Note that in the North Atlantic $40 \mathrm{~m}$ was the shallowest bottle depth, and hence actual dissolved stoichiometries could have even higher values if depths above $40 \mathrm{~m}$ were available for the five-point regression analysis. Particulate $\mathrm{Co}$ and $\mathrm{P}(p \mathrm{Co}$ and $p \mathrm{P})$ concentrations increased towards the surface with increasing photosynthetic activity $(\mathrm{Fig} .7 \mathrm{~b}, \mathrm{c})$. The resulting $p \mathrm{Co}: p \mathrm{P}$ ratios were similar to those estimated from the $\mathrm{dCo}: \mathrm{dP}$ profile-based slope analyses, approaching $\sim 350-400 \mu \mathrm{mol} \mathrm{mol}^{-1}$ (comparison of Fig. $7 d$ and e). These observations were consis- tent with the high $\mathrm{dCo}: \mathrm{P}$ value of $560 \mu \mathrm{mol} \mathrm{mol}^{-1}$ from a surface transect ( $5 \mathrm{~m}$ depth) across the equatorial Atlantic, which appeared to be an outlier due to being an order of magnitude higher than other literature values, as mentioned above (Saito and Moffett, 2002). These oceanic upper water column $p$ Co values here appear to be largely associated with biogenic material: Twining et al. (2015) reported $p$ Co in the upper $100 \mathrm{~m}$ to be largely labile by their leaching methods, and analysis of the small size fraction from McLane pump samples found the lithogenic component to be a minority component in most samples, particularly in shallower samples (all samples shallower than $400 \mathrm{~m}$ depth had a minority lithogenic contribution; see Sect. 3.3 below). Based on these observations and calculations, the assumption of $p \mathrm{Co}$ being dominated by biogenic and authigenic components appears reasonable for our stoichiometric discussion, although the observation of the presence of this minority component of lithogenic particulate cobalt in the deep ocean could contribute a slowly dissolving gradual source of dCo in the interior ocean that could be further studied, consistent with prior 
(a)
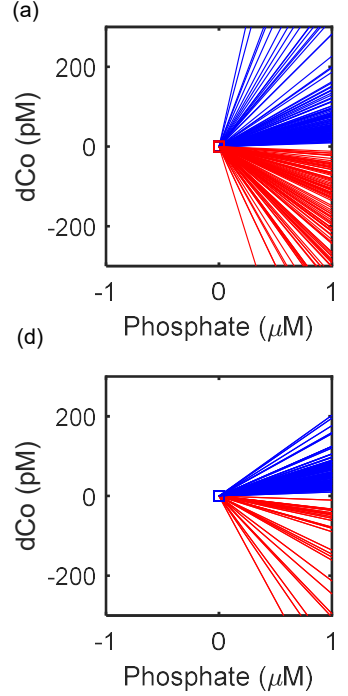

(b)
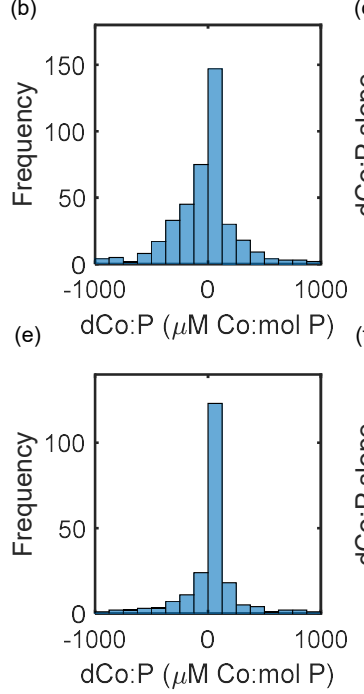

(c)
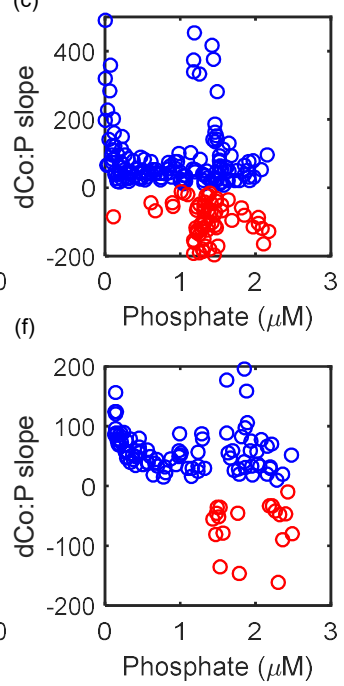

(g)

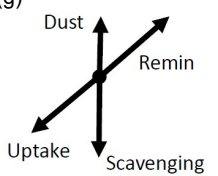

Figure 4. Vectors measured by five-point moving window linear regression for (a) the North Atlantic GA03/3e zonal section, and (d) the South Atlantic GAc01 zonal section. Blue and red colors correspond to the positive and negative slopes as described in Fig. 3. Vector lengths were made larger than the plot since they do not present information in this diagram. Histograms of frequencies of dCo: $\mathrm{P}$ slopes for the (b) North and (e) South Atlantic. dCo:P slopes relative to phosphate abundances in the (c) North and (f) South Atlantic, with increasing ratios observed as phosphate is depleted. (g) Schematic of idealized vectors for processes that influence dissolved cobalt (modified from Noble et al., 2008). Water mass mixing is not included since its contribution ratio can vary and because it is not a process that is capable of shifting these elements between dissolved and particulate phases.
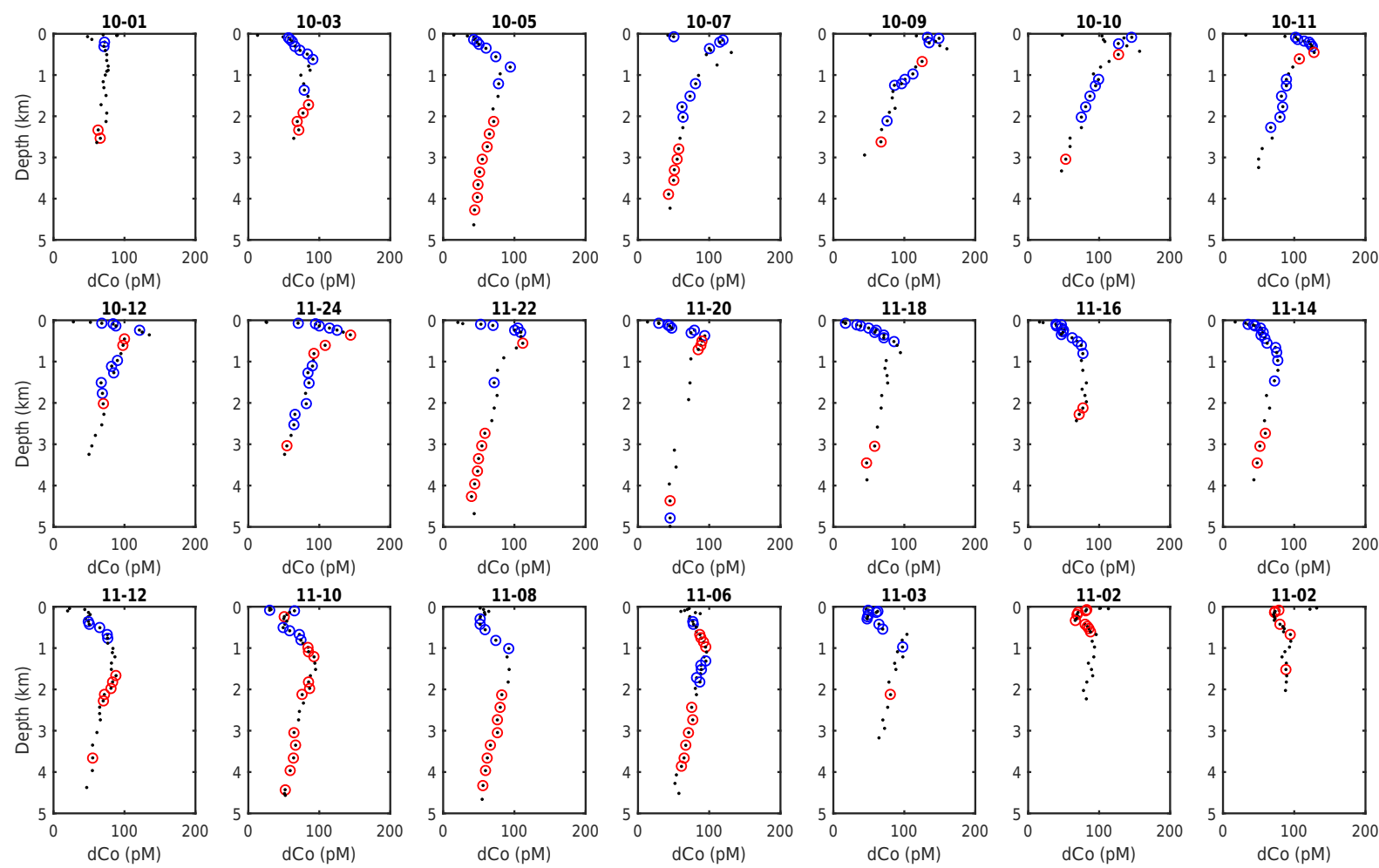

Figure 5. Vertical profiles of dissolved cobalt (pM) versus depth (m) from the North Atlantic GA03/3_e section (black symbols) with stations listed above by expedition year (first two digits for USGT10 and 11) and station number (last two digits), separated by a dash. Blue and red overlaid circles represent positive and negative slopes by linear regression $(-0.7<r>0.7)$, to indicate phytoplankton/remineralization and scavenging processes, respectively. 

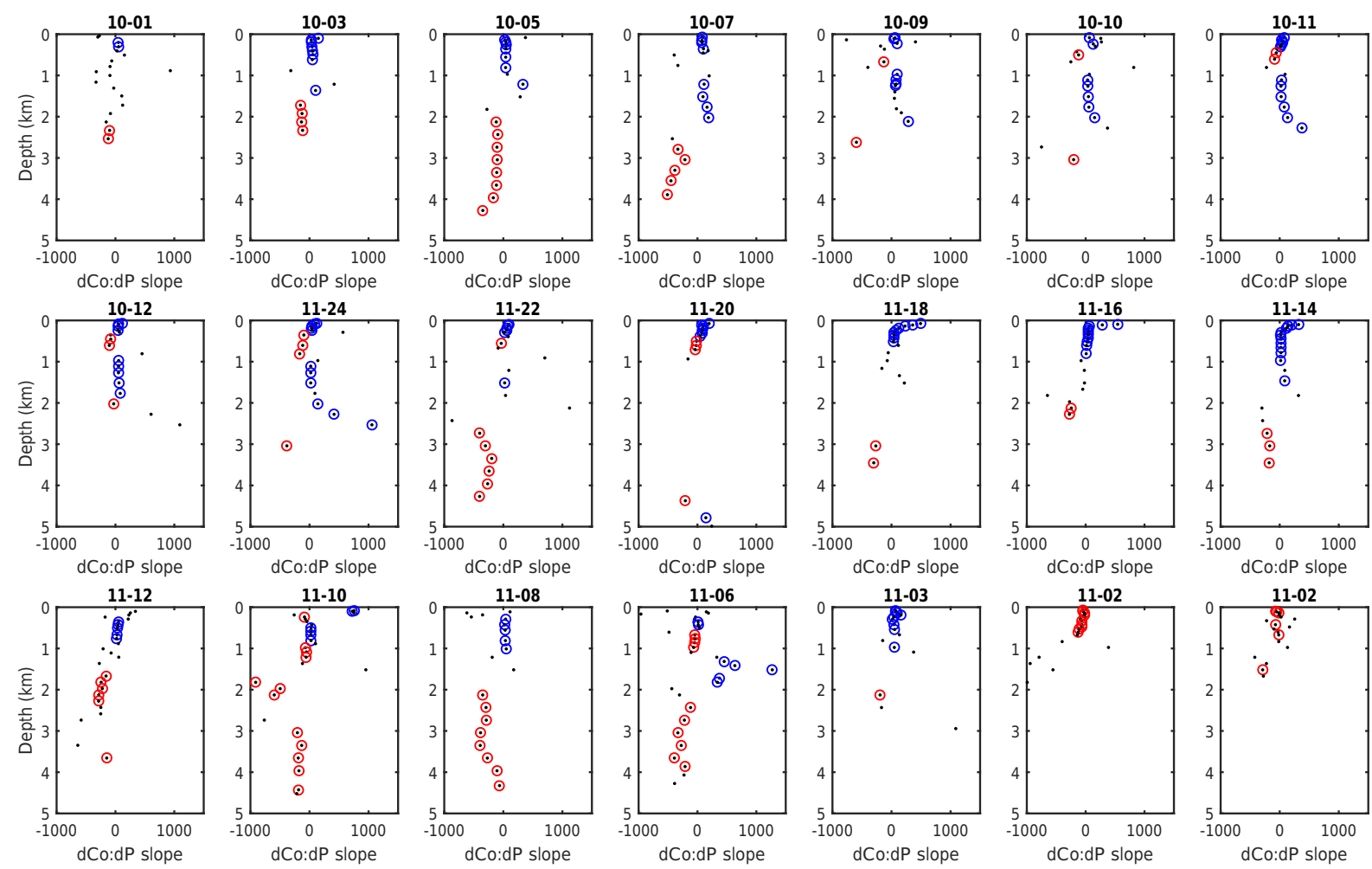

Figure 6. Vertical profiles of dCo: P stoichiometry, as calculated by five-point linear regressions (see "Materials and methods") for each of the GA03/3_e stations with stations listed above by expedition year (first two digits for USGT10 and 11) and station number (last two digits), separated by a dash. Blue symbols indicate positive slopes with associated $r$ values $>0.7$. Red symbols indicate slopes with associated $r$ values $<-0.7$. There was significant geographical heterogeneity in stoichiometry. Most stations showed nutrient-like positive slopes in the upper water column, and scavenged negative slopes in the mesopelagic and deeper depths. Other variations with some stations showing only scavenged negative (red) slopes (11-02,11-01), particularly in the North American coastal region, while other regions show alternating positive and negative slopes, likely indicative of subducted water masses (11-06, 11-24). Also, in the photic zone of stations 11-18, 11-16, and 11-14 there is an increase (an acceleration) of $\mathrm{dCo}: \mathrm{P}$ stoichiometries towards the surface. Some data points do not appear (e.g., stations 11-18 and 11-20) due to being off-scale and below threshold.

field and laboratory observations (Noble et al., 2017; Mackey et al., 2015).

Interestingly, in some regions positive $\mathrm{dCo}$ : $\mathrm{P}$ slopes were also observed below the "cobalt-cline" such as in the eastern basin of the North Atlantic (e.g., Station 10-10, Figs. 56), typically below $1000 \mathrm{~m}$. This trend could reflect the influence of export and remineralization of particles after they pass through the oxygen minimum zone where remineralization was slowed by lower oxygen abundance, contributing an addition of $\mathrm{dCo}$ and phosphate overlaid on the small $\mathrm{dCo}$ inventory.

\subsubsection{Observations and explanations for the acceleration of $\mathrm{dCo}: \mathrm{P}$ stoichiometries}

In addition to observations of high cobalt stoichiometries, the profile-based regression approach also revealed a progression of successively increasing $\mathrm{dCo}: \mathrm{P}$ slopes, or acceleration of $\mathrm{dCo}: \mathrm{P}$, towards the ocean surface. This use of the term acceleration here is comparable to its use in physics, where velocity is the distance covered per unit time (first derivative), and acceleration is defined as increases in velocity (second derivative). These velocity values were approximated simply by calculating the slope of tangents by the profile-regression analysis, and the stoichiometric acceleration can then be observed in the coherent increasing trends in these stoichiometric "velocities" with shallower depths. Similarly decelerating stoichometries were observed moving into the ocean interior. The USGT11 stations 14, 16 , and 18 described above with depleted phosphate displayed this dCo: $\mathrm{P}$ acceleration towards the surface (Fig. $7 \mathrm{~d}$ ), increasing by $1.8 \mu \mathrm{mol} \mathrm{mol}^{-1} \mathrm{~m}^{-1}$ between 288 and $40 \mathrm{~m}$, or $450 \mu \mathrm{mol} \mathrm{mol}^{-1}$ within the upper $250 \mathrm{~m}$ of Station 18 . Surveying the vertical profiles of $\mathrm{dCo}: \mathrm{P}$ slopes (Fig. 6), a number of stations included in this study display increasing $\mathrm{dCo}: \mathrm{P}$ stoichiometry towards the water-atmosphere interface, consistent with the acceleration of $\mathrm{dCo}: \mathrm{P}$ data. This acceleration of the dissolved cobalt stoichiometry towards the surface was greater in the North Atlantic relative to the South 
(a)

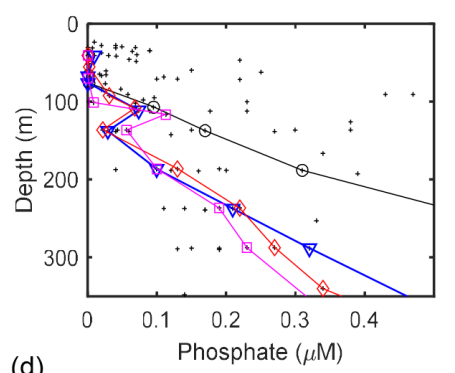

(d)

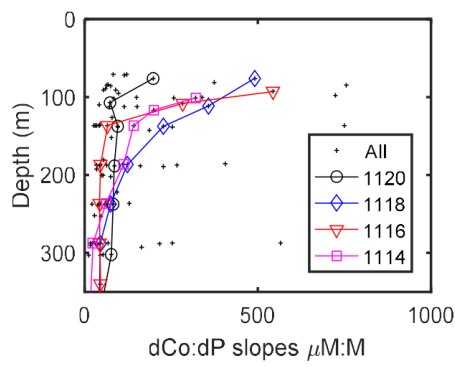

(b)

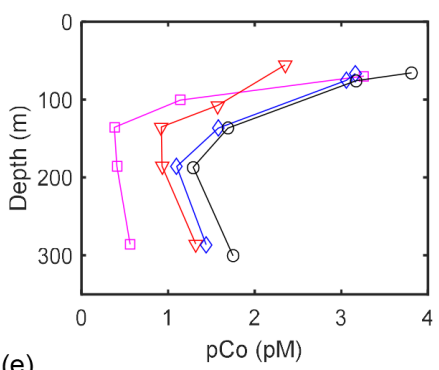

(e)

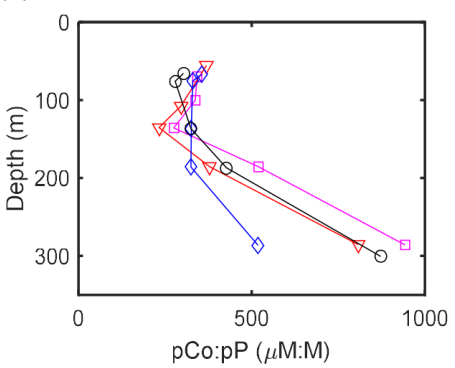

(c)

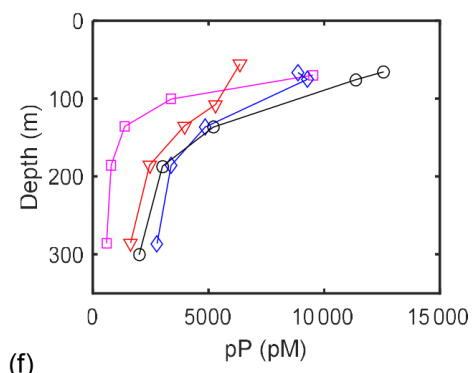

(f)

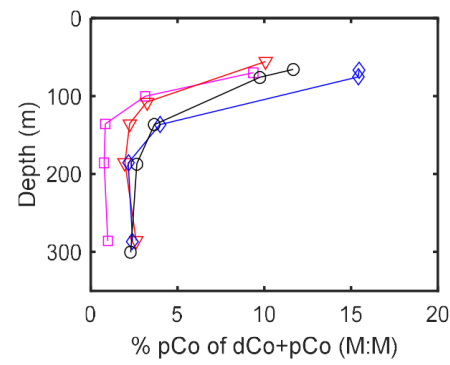

Figure 7. Dissolved $(\mathrm{dCo})$ and particulate $(p \mathrm{P})$ cobalt and phosphate concentrations and ratios at subtropical gyres stations 14,16 , 18, and 20 from USGT-2011. (a) Phosphate profiles in the upper $350 \mathrm{~m}$ for these four stations were low compared to all stations on the GA03/3_e expedition (small dots). (b) Particulate cobalt ( $p \mathrm{Co}$ ) profiles (from the Go-Flo filters). (c) Particulate phosphate ( $p$ P) profiles (from the Go-Flo filters). (d) dCo: P slopes generated by profile-regression analyses towards the surface, where each depth represents the mid-point of five depths used in the profile regression. (e) Ratios of $p \mathrm{Co}: p \mathrm{P}$ decrease towards the surface as they transition from being dominated by manganese oxide particles at depth, but remain high relative to dissolved stoichiometries (Table 1) and culture studies at values of $\sim 350-$ $400 \mu \mathrm{mol} \mathrm{mol}^{-1}$. (f) Percent of $p \mathrm{Co}$ of the cobalt inventory $(\mathrm{dCo}+p \mathrm{Co}$ ) revealed $p$ Co to reach values as high as $\sim 10 \%$ in the upper euphotic zone, providing greater leverage for altering the $\mathrm{dCo}$ : $\mathrm{dP}$ slopes.

Atlantic (Fig. 4c, f), where dCo: $\mathrm{P}$ increased as with decreasing phosphate concentrations, reaching maximum values of approximately 500 and $150 \mu \mathrm{mol} \mathrm{mol}^{-1}$, respectively.

Together, these results imply the presence of a higher ecological stoichiometry of Co in the oligotrophic gyre created by resident microbial and phytoplankton communities imprinting themselves on the dissolved phase. There are three co-occurring phenomena that together likely explain these observations of high and accelerating $\mathrm{dCo}: \mathrm{P}$ stoichiometries in the upper oceanic photic zone: (1) decreased biological use of phosphate due to its depletion in the upper water column and through sparing mechanisms in phytoplankton, (2) substitution of Co for $\mathrm{Zn}$ within metalloenzymes as $\mathrm{Zn}$ depletion occurs in the upper photic zone, and (3) enhanced Co and $\mathrm{Zn}$ metal nutritional needs due to biosynthesis of the metalloenzyme alkaline phosphatase as a strategy for liberating dissolved organic phosphorus upon phosphate scarcity. The first explanation would decrease the denominator, while the latter two would act to increase the numerator of the $\mathrm{dCo}: \mathrm{P}$ relationships.

With regard to the first process, the upper photic zone has highly depleted soluble reactive phosphorus abundances (Fig. 7a). This is particularly true in the North Atlantic, which has the lowest reported phosphate abundances in the ocean (Wu et al., 2000). The depletion of phosphate by phy- toplankton and microbial use in the upper photic zone can result in a lower stoichiometric $\mathrm{P}$ use (relative to that of Co here), and could thus induce the positive trajectory of $\mathrm{dCo}: \mathrm{P}$ through microbial loop remineralization by effectively lowering the $\mathrm{dCo}: \mathrm{P}$ denominator. There is biochemical evidence to support this phenomenon, where many phytoplankton, including cyanobacteria and diatoms, decrease their $\mathrm{P}$ stoichiometry by sparing (conserving) phosphate intracellularly through the substitution of sulfolipids for phospholipids in their membranes. This effectively lowers their phosphate requirement and deviates from Redfieldian N:P stoichiometries (Van Mooy et al., 2006). In addition to lipid measurements, the biosynthesis proteins for sulfolipids also increase in abundance due to P scarcity in the North Pacific Ocean (Saito et al., 2014). As a result, the marine cyanobacteria that dominate the oligotrophic gyres of the Atlantic have a large dynamic range for their phosphate stoichiometry: cellular composition of axenic cultures of Prochlorococcus and Synechococcus showed 3.8-5.6-fold decreases in C : $\mathrm{P}$ ratios between $\mathrm{P}$-replete and $\mathrm{P}$-limited conditions $(\mathrm{C}: \mathrm{P}$ ratios limited: 46, 50 and 63; replete: 179, 290, and 301 for MED4, 8102 , and 8103, respectively; Bertilsson et al., 2003). In addition, there is field evidence supporting this P-sparing phenomenon in the North Atlantic cyanobacterial populations, including a 2-fold decrease in Synechococcus P content in 
the low-nutrient anticyclonic eddy in the Sargasso (Twining et al., 2010), and with picocyanobacteria showing $\mathrm{C}$ : $\mathrm{P}$ ratios elevated by as much as 10 -fold over Redfield values in surface and deep (142 m) samples (Grob et al., 2013). In summary, this replacement of sulfur for phosphorus within membranes would increase the upper photic zone $\mathrm{dCo}$ : $\mathrm{P}$ stoichiometry by depressing the denominator.

The second and third processes (increased biotic cobalt demand and substitution of cobalt for zinc) that can explain accelerating $\mathrm{dCo}: \mathrm{P}$ stoichiometries are closely related, and likely occur simultaneously. The preferential use of $\mathrm{P}$ explanation described above does not appear to entirely explain the $\mathrm{dCo}$ : P relationships because particulate cobalt, likely reflecting the microbial community (filtered by $0.2 \mu \mathrm{m}$ membranes), both increased in absolute concentration towards the surface (Fig. 7b) and had a high $p \mathrm{Co}: p \mathrm{P}$ biomass ratio of $\sim 300 \mu \mathrm{M}: \mathrm{M}$ (Fig. 7d). Notably, these particulate values were similar to the dissolved phase profile-regression results (Figs. 7d; 4c, f), and were roughly an order of magnitude higher than the aggregate regression reported above, implying the dissolved phase stoichiometry was reflecting a high cellular content of Co in the protoplasm in the upper water column of this region. Moreover, while the particulate reservoir of cobalt is generally a small fraction of the total cobalt reservoir (defined as $\mathrm{dCo}+p \mathrm{Co}$ ), in the upper $70 \mathrm{~m} p$ Co was typically greater than $10 \%$ of the cobalt reservoir due to high microbial activity, increased Co demand, and drawdown of dCo (Fig. 7f).

These results were also consistent with additional data collected across the broad lateral gradients of the North Atlantic zonal GA03 transect, where elevated $p \mathrm{Co}: p \mathrm{P}$ in labile particulate matter was observed in the low-phosphate mid-subtropical gyre region, and phytoplankton cells were observed to have a high stoichiometry of $\sim 400 \mu \mathrm{mol} \mathrm{mol}^{-1}$ $\mathrm{Co}: \mathrm{P}$, as measured by synchrotron X-ray fluorescence (SXRF) at Station 2011-2016 (Twining et al., 2015, their Fig. 11c). As a result, the large relative size of the $p$ Co reservoir will rapidly impose changes on the $\mathrm{dCo}: \mathrm{dP}$ ratio through the continual activity of the microbial loop (uptake and grazing/lysis) that is known to turn over the entire euphotic zone small particle reservoir (represented by picoplankton) every 2 days in oligotrophic regions (CavenderBares et al., 1999; Mann and Chisholm, 2000; Vaulot, 1995). As the picoplankton and other microbial populations that dominate the subtropical gyres are continually grazed and lysed, the particulate $p$ Co reservoir is released back to the $\mathrm{dCo}$ phase. As the percentage of $p$ Co to dCo increases towards the surface, the particulate phase gains additional "leverage" with which to alter the stoichiometry of the dissolved phase.

\subsubsection{Connecting metal distributions to metaproteomic metalloenzyme distributions and the potential for cobalt-zinc substitution}

Together these results imply high Co demand in the upper photic zone in the surface Atlantic Ocean. Why might this higher Co use occur? The enhanced $\mathrm{dCo}: \mathrm{P}$ and $p \mathrm{Co}: \mathrm{P}$ observed in the upper photic zone likely reflects an increased cobalt requirement in the microbial community. While the marine cyanobacteria Prochlorococcus and Synechococcus both have an absolute requirement for $\mathrm{Co}$, where they cannot survive without it nor can they substitute $\mathrm{Zn}$ for Co (Saito et al., 2002; Sunda and Huntsman, 1995), this absolute requirement appears to be a relatively minor component of their cellular cobalt quota. Additional biochemical functions for Co have been hypothesized, in particular the use of cobalt in alkaline phosphatase and carbonic anhydrase (Jakuba et al., 2008; Saito et al., 2002, 2003). The alkaline phosphatase enzyme appears to be particularly important in the Atlantic oligotrophic gyres where soluble reactive phosphate is extremely low (Duhamel et al., 2010; Dyhrman et al., 2002; Jakuba et al., 2008), and low phosphate availability causes an increase in the biosynthesis of this enzyme in order to allow phytoplankton to liberate phosphorus from the dissolved organic phosphate (DOP) chemical reservoir (Dyhrman et al., 2012). Indeed, there have even been reports that the activity of organic phosphorus acquisition may be constrained by zinc availability: recent field studies in the North Atlantic observed stimulation of alkaline phosphatase activity following the addition of zinc (Mahaffey et al., 2014).

There are two isoforms of the alkaline phosphatase enzyme, the zinc PhoA and recently characterized iron-calcium PhoX (Duhamel et al., 2010; Shaked et al., 2006; Yong et al., 2014). PhoX was previously thought to be a calciumonly enzyme (Kathuria and Martiny, 2011). While PhoA is known to be a zinc metalloenzyme in model organisms (Kim and Wyckoff, 1991), cobalt has been demonstrated to substitute for the catalytic center in the hyperthermophilic microbe Thermotoga maritima (Wojciechowski et al., 2002). It is unknown at this time if this cobalt-zinc substitution can occur in marine microbes: the metal center of marine cyanobacterial PhoA has yet to be determined under natural conditions in the laboratory or field environment. While the PhoX isoform's use of iron has been hypothesized to lessen its dependence on PhoA in iron-rich waters (Mahaffey et al., 2014), PhoA was observed to be more prevalent in Synechococcus proteomes under low phosphate relative to PhoX even in replete iron conditions, implying PhoA could be particularly important for DOP utilization (Cox and Saito, 2013). Also consistent with the use of $\mathrm{Zn}$ (and perhaps $\mathrm{Co}$ ) was a lower abundance of PhoA at low $\mathrm{Zn}$ while still at low $\mathrm{P}$ availability, implying that the expression of PhoA was co-induced by low P and high Zn (Cox and Saito, 2013). The influence of simultaneously low Co and phosphate has been little studied in marine cyanobacteria. The dissolved iron abundances of 
these stations in the central North Atlantic were elevated due to aeolian deposition with near surface samples $(\sim 2 \mathrm{~m})$ being greater than $0.6 \mathrm{nM}$ between stations $11-12$ and 11-20 (Hatta et al., 2015), although excess strong iron organic ligands were detected throughout these regions as well (Buck et al., 2015), potentially reducing iron bioavailability.

We hypothesize that this elevated Co use in the upper water column is being driven by PhoA alkaline phosphatase. To support this hypothesis, we present novel metaproteomic data from samples taken at the BATS station in the North Atlantic Subtropical Gyre during April of 2015 (the same location as GEOTRACES Station 11-10) that showed high abundances of alkaline phosphatases (PhoA) in the upper euphotic zone (Fig. 8c), where phosphate was depleted (Fig. 8a). Two distinct cyanobacterial alkaline phosphatases were detected, both the PhoA isoform, from Prochlorococcus and Synechococcus species, corresponding to sequences from Atlantic isolates NATL1 and WH8102. The Synechococcus PhoA isoform was more abundant in the upper photic zone, while the Prochlorococcus PhoA showed a maximum at a depth of $82 \mathrm{~m}$, consistent with the depth distributions of marine cyanobacteria in this region (Olson et al., 1990). Since PhoA is a metalloenzyme with two zinc atoms per protein, these metaproteomic results imply an increasing need for a divalent cation, zinc or perhaps cobalt if substitution was occurring, to populate this enzyme in the upper photic zone. Note that these protein profiles are relative abundance units of total spectral counts, where each spectra matched to a peptide constitutes a spectral count. Future analysis by calibrated targeted metaproteomics will allow protein concentrations and their metal content to be estimated (Saito et al., 2015, 2014). The PhoX iron-calcium isoform was not detected in the water column in this preliminary analysis, although this negative result should not be interpreted as the protein being absent from the ecosystem since it could reflect lack of matching PhoX sequences or annotations in our database. While this BATS metaproteome dataset was geographically and temporally different from that of the NAZT section, it was within the North Atlantic Subtropical Gyre with its characteristically low phosphate abundances. The sulfolipid biosynthesis protein (UDP-sulfoquinovose) also showed a surface maximum at this BATS station (Fig. 8b), demonstrating that this phosphate-sparing mechanism was being engaged and that we would also expect decreases in cellular phosphate quotas in the marine cyanobacteria as described above. The lower phosphate inventory of the North Atlantic Subtropical Gyre versus the South Atlantic Subtropical Gyre could also explain the differences in $\mathrm{dCo}: \mathrm{P}$ stoichiometry maxima observed between basins (Fig. 4c, f), where increased P scarcity could result in enhanced $\mathrm{dCo}: \mathrm{P}$ stoichiometries through the three processes described above.

Could zinc have been scarce enough to encourage cobaltzinc substitution within metalloenzymes such as alkaline phosphatase? Zinc can be exceedingly scarce in the upper photic zone due to phytoplankton uptake and export, partic- ularly in the subtropical gyres (Bruland and Franks, 1983). To examine this possibility, we compared the distributions of dissolved cobalt, zinc, and cadmium ( $\mathrm{Cd}$ can substitute for $\mathrm{Zn}$ in diatom carbonic anhydrases; Lane et al., 2005) in the center of the North Atlantic Subtropical Gyre, again at USGT11 stations 14, 16, and 18 (Fig. 9a-c). While dissolved $\mathrm{Zn}$ was the most abundant of the three at intermediate depths (18-fold more dZn than dCo at $1000 \mathrm{~m}$, Fig. 9a), it became depleted within the upper $100 \mathrm{~m}$ to the extent that its concentrations were reduced to less than 2 times that of $\mathrm{Co}$ (ratios of $\mathrm{dCo}: \mathrm{dZn}$ are greater than 0.5, Fig. 9g). Dissolved Cd was so depleted in the photic zone that dCo actually became 50-fold more abundant than $\mathrm{dCd}$ in the photic zone (Fig. 9h), and the $\mathrm{dCd}$ was typically more than 100 -fold lower than $\mathrm{dZn}$ in the upper euphotic zone (Fig. 9i). Dissolved zinc and cadmium are also typically bound by strong organic complexes in the oceanic euphotic zone (Bruland, 1992, 1989; Ellwood, 2004), which would greatly reduce the abundance of their inorganic species and their resultant bioavailability to phytoplankton as observed in culture studies (Sunda and Huntsman, 1995, 2000).

Development and application of new metalloproteomic techniques (Aguirre et al., 2013) could determine if cobalt can substitute for zinc within the PhoA metalloenzyme of the abundant cyanobacteria Prochlorococcus and Synechococcus that dominate the oligotrophic euphotic zone when zinc and cobalt become similar in abundance, consistent with observations of a cobalt-PhoA in a hyperthermophillic bacterium (Wojciechowski et al., 2002). This comparison to proteomic results also demonstrates the value in developing future "BioGEOTRACES/OceanOmics" efforts that aim to connect nutrient and micronutrient distributions directly with the proteins that require them, as well as with additional biochemical, molecular, and cellular information about the resident biota.

\subsubsection{Excess $\mathrm{Zn}$ uptake in the lower photic zone creating $\mathrm{dZn}$ convex and dCo concave kinks}

Interestingly, $\mathrm{dZn}$ and $\mathrm{dCd}$ have concave kinks when plotted against phosphate in this region (Fig. 9d, e). This is in contrast to the convex kinks observed above in $\mathrm{dCo}: \mathrm{P}$ space (Fig. 2a, b). It has been previously suggested that differences in the relationships of $\mathrm{Co}, \mathrm{Cd}$, and $\mathrm{Zn}$ relative to phosphate in the Ross Sea and North Pacific are indicative of variations in phytoplankton metal usage (Saito et al., 2010; Sunda and Huntsman, 2000). One explanation for this phenomenon is that there is excess biological uptake (defined as uptake in excess of the cellular biochemical requirements) at the base of the euphotic zone, resulting in $\mathrm{Zn}$ and $\mathrm{Cd}$ becoming rapidly depleted towards the surface to concentrations approaching Co (Saito et al., 2010). This depletion of $\mathrm{Zn}$ and $\mathrm{Cd}$ can then create conditions amenable to Co substitution in the upper euphotic zone. This excess $\mathrm{Zn}$ uptake and Co substitution scenario seems particularly plausible in these oligotrophic 
(a)

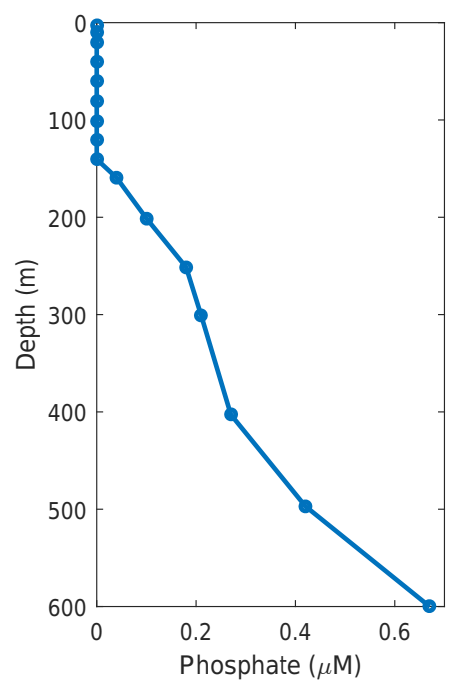

(b)

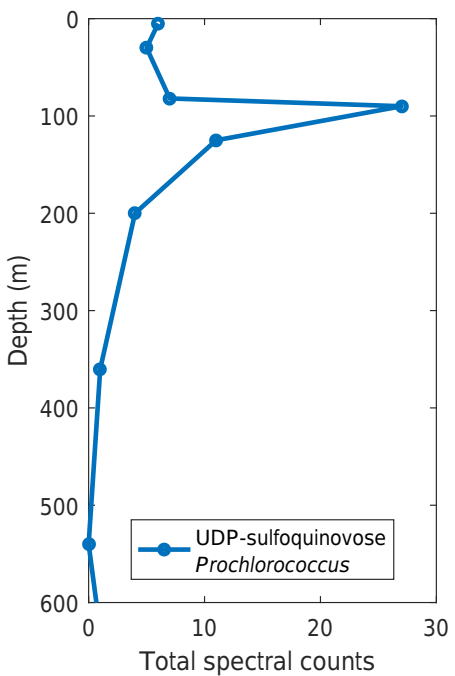

(c)

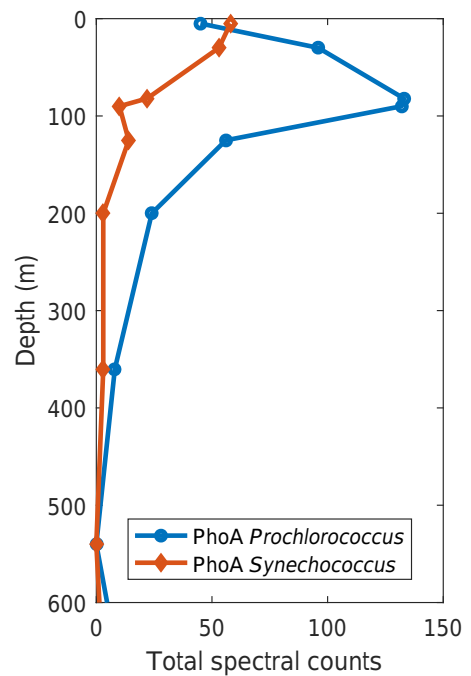

Figure 8. Profiles of (a) phosphate, (b) UDP-sulfoquinovose enyzme involved in sulfolipid biosynthesis, and (c) alkaline phosphatase enzymes (PhoA isoform) at the BATS station in April 2015 from the marine cyanobacteria Prochlorococcus and Synechococcus as determined by global metaproteomic analyses. Proteins are in units of unnormalized spectral counts. PhoA is typically considered a zinc enzyme in model terrestrial organisms, but has been found to be a Co enzyme in a hydrothermal bacterium.
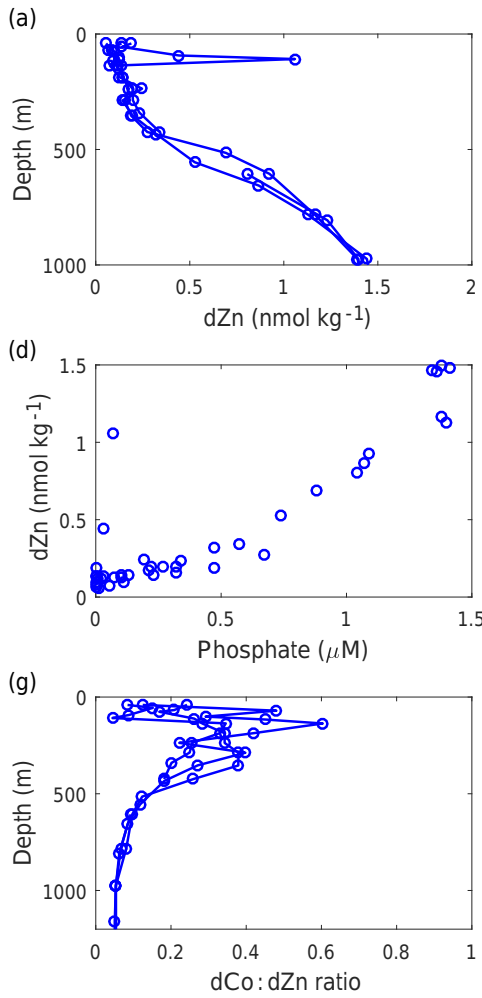

(b)

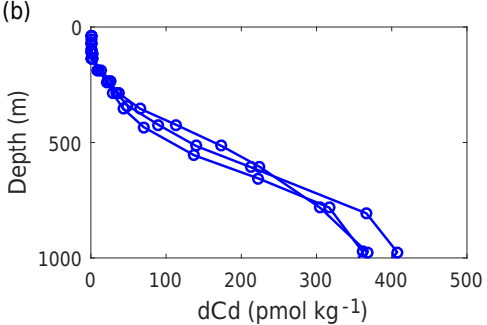

(e)

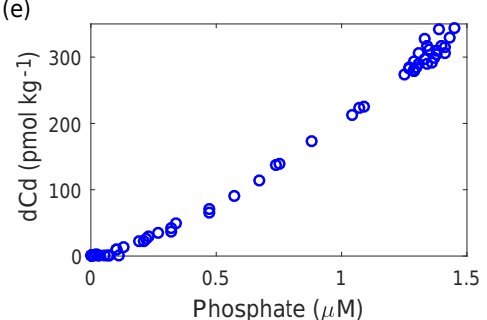

(h)

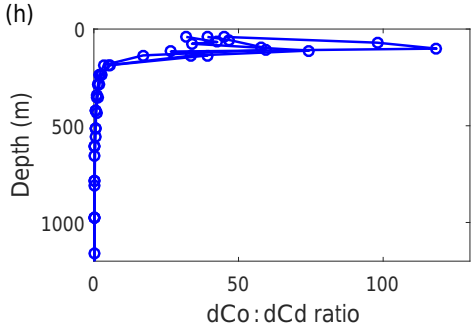

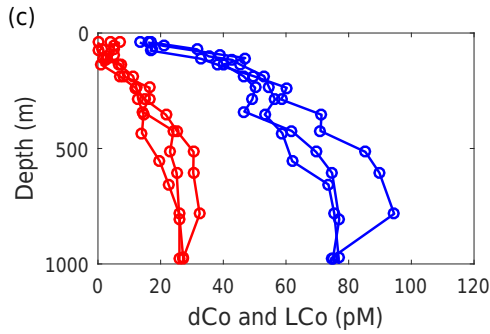
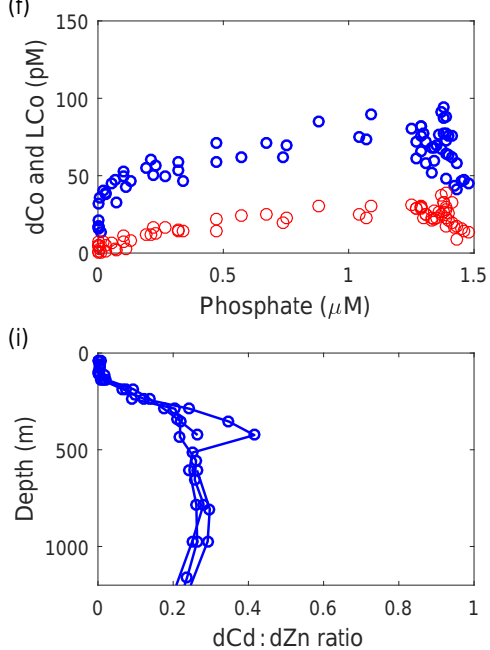

Figure 9. Zn, Cd, and Co and labile cobalt distributions (a-c), relationships with phosphate (d-f), and metal-metal ratios (g-i) in the central North Atlantic Subtropical Gyre at USGT-2011 stations 14, 16, and 18. Dissolved cobalt is in blue and labile cobalt is red in panels (c) and (f). $\mathrm{dZn}$ and dCd were depleted at the base of the euphotic zone, resulting in dCo being $\sim 40 \%$ of the abundance of dZn and 1-2 orders of magnitude more abundant than $\mathrm{dCd}$ within the euphotic zone. $\mathrm{dZn}$ and $\mathrm{dCd}$ have concave relationships with phosphate, while dCo and LCo have convex relationships, implying faster biological drawdown of use of $\mathrm{dZn}$ and dCd relative to phosphorus, and vice versa for $\mathrm{dCo}$. 
Atlantic Ocean gyre locations as well, leaving Co to have an important nutritional role and high stoichiometric values in the upper water column of this region. Cellular $\mathrm{Zn}: \mathrm{P}$ values in individual phytoplankton cells across the GA03 North Atlantic transect were also measured by SXRF. $\mathrm{Zn}$ : $\mathrm{P}$ ratios were generally elevated near continental margins, and the lowest values were observed in the mid-subtropical gyre at Station 2011-2016, where cellular Co: $\mathrm{P}$ was elevated, consistent with Co substitution for Zn use (Twining et al., 2015, their Fig. 11f). It is noteworthy that these depletion and kink features are occurring much deeper in the Atlantic subtropical gyres than in the Ross Sea and North Pacific, due to the deep euphotic zones created by very low biomass and high light transmission, and with nutrients supplied primarily by slow vertical diffusion processes.

\subsubsection{Comparison of field ecological stoichiometries to cellular quotas and implications for biological use of biochemical substitution}

The range of $\mathrm{dCo}: \mathrm{P}$ stoichiometric values estimated for the aggregate and profile regressions for the North and South Atlantic datasets were at the low and mid-range of the measured cobalt cellular quotas in phytoplankton grown at very low zinc abundances, respectively. Sunda and Huntsman reported Co:C quotas for the coccolithophore Emiliania huxleyi, the diatoms Thalassiosira pseudonana and Thalassiosira oceanica, and the cyanobacterium Synechococcus bacillaris (Sunda and Huntsman, 1995). When converted to Co: P, using an assumed $\mathrm{C}: \mathrm{P}$ Redfield ratio of $106: 1$, the quotas over increasing cobalt and scarce $\mathrm{Zn}^{2+}\left(10^{-13} \mathrm{M}\right)$ ranged $77-$ $2713,42-1314,284-2120$, and 8.5-151 $\mu \mathrm{mol} \mathrm{Co} \mathrm{mol}^{-1} \mathrm{P}$, in the order of phytoplankton listed above. When zinc concentrations increased in those experiments, Co quotas decreased by several orders of magnitude in the first three eukaryotic phytoplankton strains, with no Zn quota data available for Synechococcus. Unfortunately, none of these culture experiments were conducted under P-limiting conditions that would induce phosphate-sparing mechanisms and result in an enhanced Co or Zn stoichiometry. In a separate study, the coccolithophore Emiliana huxleyi was found to have a $16 \%$ increase in $\mathrm{Zn}$ cellular content when switched from growing on inorganic phosphate to organic phosphate (Shaked et al., 2006). However it is difficult to compare these results to the cyanobacteria that tend to dominate the Atlantic Ocean subtropical gyres since many cyanobacteria appear to have little demand for zinc when grown in inorganic $\mathrm{P}$ conditions (Saito et al., 2002; Sunda and Huntsman, 1995), although Synechococcus does show enhanced growth with zinc in media which includes organic P (Cox and Saito, 2013). Based on this comparison and the discussion above, we interpret that there may well have been significant substitution of Co for a combined $\mathrm{Zn} / \mathrm{Co}$ requirement, particularly in the upper water column, where $\mathrm{dZn}$ was roughly equivalent in concen- tration to $\mathrm{dCo}$, assuming the enzyme(s) is capable of such a substitution.

\subsubsection{The accelerating Co stoichiometry phenomenon in the context of Redfield theory}

The accelerating dissolved Co stoichiometry is a surprising feature that likely reflects an increasing influence of a high $p$ Co quota on the dissolved reservoir towards the sunlit surface waters. To make sense of this we can reflect on Redfield et al.'s early writing on the dissolved and particulate $\mathrm{C}, \mathrm{N}$, and $\mathrm{P}$ sharing stoichiometric ratios, where they wrote: "Elements are withdrawn from sea-water by the growth of marine plants in the proportions required to produce protoplasm and are returned to it as excretions and decomposition products of an equally specific nature. ... Since the elements required for the construction of protoplasm are drawn from the water in proportions which have some uniformity, they are distributed in somewhat similar patterns by the biochemical circulation." (Redfield et al., 1963). In this writing Redfield et al. emphasize not only a general ("statistical") uniformity of stoichiometry but also a bidirectional flow of nutrients between dissolved and particulate phases, and its subsequent influence on seawater composition. The often observed stoichiometric equivalence in dissolved and particulate phases thus requires an implicit ability of these phases to materially exchange with each other through continual cellular uptake, grazing and lysis recycling, and remineralization processes to such an extent that the dissolved and particulate stoichiometries converge on identical ratios. The small amount of material that escapes an oligotrophic euphotic zone as export flux can then act within an important gradual winnowing process where stoichiometric excesses are removed from the dissolved phase into the particulate phase and remineralized below where they may have a minor influence on the larger preformed mesopelagic inventories.

Cobalt, as one of the scarcest of inorganic nutrients, provides an interesting counter-example to Redfield's abundant macronutrients. In oceanographic contexts, while there is increasing evidence that there can be some regional variability in Redfield's stoichiometric ratios, these variations are relatively small (e.g., less than 2-fold; Martiny et al., 2013) when compared to the large multiple order of magnitude potential plasticity observed in metal usage in culture experiments (Sunda and Huntsman, 1995, 2000, 1997). Yet for trace metal micronutrients such as $\mathrm{Zn}$ and $\mathrm{Cd}$, the linear relationships between those metals and macronutrients imply a consistency (or an averaging) of stoichiometries in the oceans. In comparison, the large variability in cobalt ecological stoichiometry discussed here appears to be unusual. The situation for cobalt is extreme: not only are the dissolved $\mathrm{Co}: \mathrm{P}$ ratios so variable as to make a single uniform oceanic ratio difficult, but they also span more than an order of magnitude and, as described above, accelerate towards the surface. Such plasticity is likely enabled by the biochemical substitution strategies 
deployed by euphotic zone phytoplankton described above for Co and $\mathrm{Zn}$, and the stoichiometry of these elements has been unequivocally demonstrated in the laboratory to be able to shift considerably (Sunda and Huntsman, 1995). If the considerably lower aggregate regression stoichiometries described above reflect much lower biochemical requirements in the base of the euphotic zone, it seems likely that the Atlantic, with its particularly low phosphate availability, results in a diversity of cobalt stoichiometries from the base of the euphotic zone (where $\mathrm{P}$ is abundant) to the surface, where $\mathrm{P}$ scarcity results in the three mechanisms described above (see Sect. 3.2.3) simultaneously contributing to elevated Co:P. As a result, we are able to observe the pull of the upper photic zone on the biological stoichiometry of the dissolved phase stoichiometry and its distinct acceleration towards the surface. The acceleration of $\mathrm{Co}: \mathrm{P}$ towards the surface was also supported by SXRF quota data on three stations on the GA03 North Atlantic transect, where Co quotas in cells were 2-4fold higher in the upper mixed layer compared to the deep chlorophyll maximum, and reflected the largest depth quota difference of all trace metals studied in this region (Twining et al., 2015, their Fig. 9 and Table 4).

An important general stoichiometric lesson that we can learn from cobalt is that the coupling between the dissolved and particulate phase stoichiometries is not instantaneous, with each phase having an inertia related to the size of its inventory and the extent of exchange between phases. The small size of cobalt's water column inventory, and the potential for its stoichiometry to change greatly in response to more abundant nutrients such as $\mathrm{P}$ and $\mathrm{Zn}$, erodes away at its limited inertia and results in its acceleration to catch up with the particulate phase.

The reader might have noticed that one piece of data is missing in this story: we would expect the lower euphotic zone particulate phase to also show lower Co: $\mathrm{P}$ stoichiometries associated with phytoplankton (growing in abundant $\mathrm{Zn}$ and P) and resultant lowered cellular particulate quotas, as is clearly observed in the dissolved phase (Table 1) and in culture studies (Sunda and Huntsman, 1995). However, these deeper phytoplankton stoichiometries appear to be masked by substantially higher $\mathrm{Co}$ : P stoichiometries associated with microbial manganese oxide particles that do not appear to communicate back with the dissolved phase (Fig. 7e), effectively acting as a one-way trip into the particulate phase. This provides an opportune segue to the mesopelagic and deep ocean and the unusual negative $\mathrm{dCo}: \mathrm{P}$ stoichiometries observed therein.

\subsection{Evidence for mesopelagic scavenging of cobalt in the Atlantic Ocean}

The cause of cobalt's small marine inventory is often attributed to be the result of scavenging processes that continually remove dissolved cobalt from the water column. The evidence for this process is limited to several field and labo- ratory radiotracer experiments that point to the co-oxidation of cobalt within manganese oxide particles below the photic zone (Lee and Tebo, 1994; Moffett and Ho, 1996; Tebo et al., 1984), as well as interpretation of vertical profiles with reduced cobalt at intermediate and deep depths (Noble et al., 2008, 2013; Saito et al., 2010; Saito and Moffett, 2002). This production of $\mathrm{Mn}$ oxide phases is a biological process where manganese oxides precipitate directly onto the cell surface of manganese-oxidizing bacteria (Cowen and Bruland, 1985), and hence could largely decouple $\mathrm{Mn}$ and the co-precipitated Co from phosphate as these metals are largely incorporated into the mineral phase rather than microbial biomass (see schematic Fig. 4g). Yet it was also recently suggested that scavenging may not be an important process for dissolved cobalt in the oceans, and that instead differences in deepwater concentrations are controlled by physical circulation and remineralization processes (Dulaquais et al., 2014b). In general the notion of "hybrid-type" elements that possess both nutrient-like and scavenged behaviors, including the metals $\mathrm{Fe}, \mathrm{Cu}$ and $\mathrm{Co}$, is relatively new (Bruland and Lohan, 2003; Noble et al., 2008; Saito et al., 2010), and this large dataset provides a useful opportunity to provide evidence and discussion of this phenomenon.

The profile-based regressions employed above for upper water column processes as well as particulate metal datasets can provide insight into the scavenging process. As noted above, the profile analysis, using five-point moving two-way linear regressions, identified numerous depth intervals with negative linear relationships between Co and phosphate in both the North and South Atlantic Ocean (Fig. 3.; red symbols and lines) that are distinct from the positive slope relationships attributed to uptake and remineralization processes described above (also exceeding a selected threshold correlation coefficient $(r)$ of $\geq|0.7|)$. These negative slopes can be located with their dCo concentration profiles (Fig. 5, red symbols) and their magnitude examined with depth (Fig. 6; red symbols). Note that the correlation coefficients of negative slopes are also negative (e.g., $<-0.7$ ), and only data with $r$ values above the threshold are presented.

These negative relationships are intriguing in that they deviate from the idealized downward (vertical) vector for scavenging (Fig. 4g), with measured slopes that generate "southeast" vectors in both the North and South Atlantic (Fig. 4a, $\mathrm{d}$, red vectors). These negative vectors imply the removal of dCo simultaneously with an addition of phosphate from the water column. It is difficult to envision a single process that can create this effect; however, the addition of two vectors makes this feasible: a positive remineralization vector plus a near vertical scavenging vector can reproduce both the negative vectors and their decreasing slope (becoming increasingly vertical) with depth as the remineralization contribution dissipates and approaches zero. This is demonstrated in a revised schematic (Fig. 10c) and vector addition diagrams (Fig. 10a-b) that use measured values from this study. Vector "endmembers" for remineralization of euphotic zone 

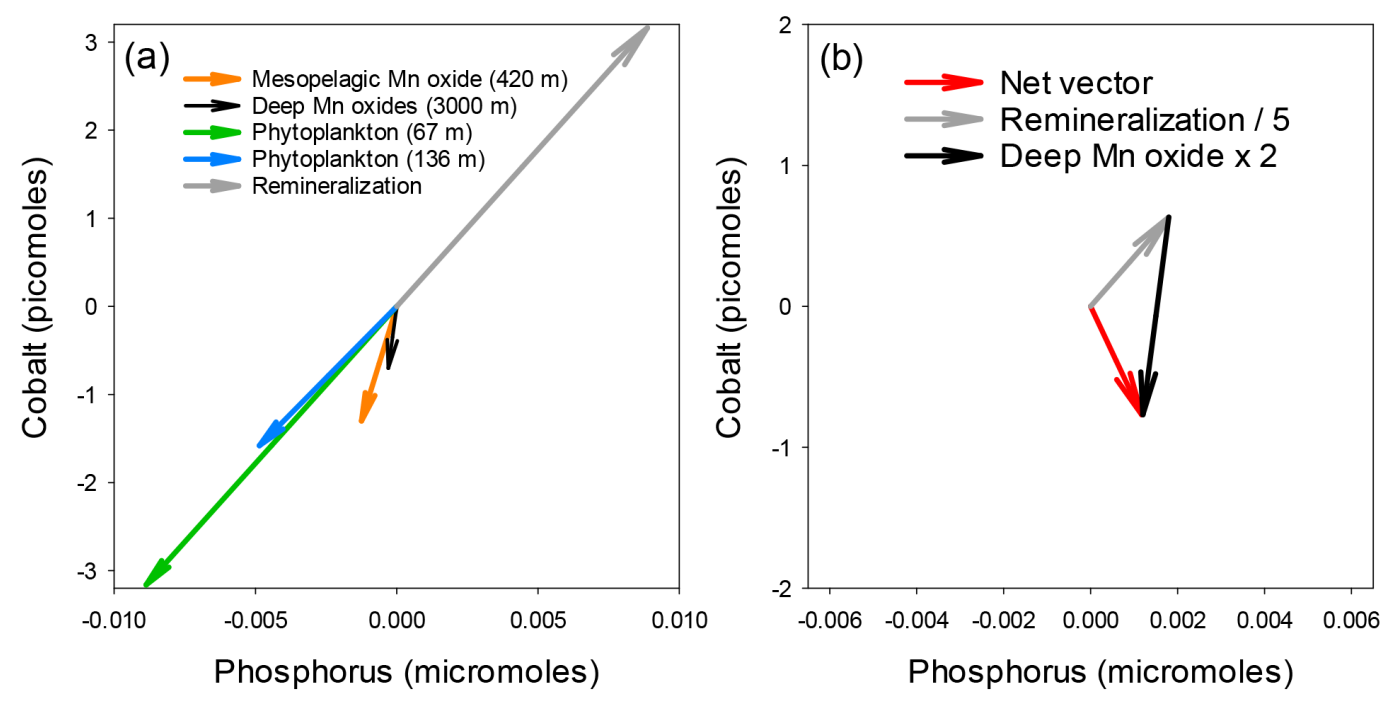

(c)

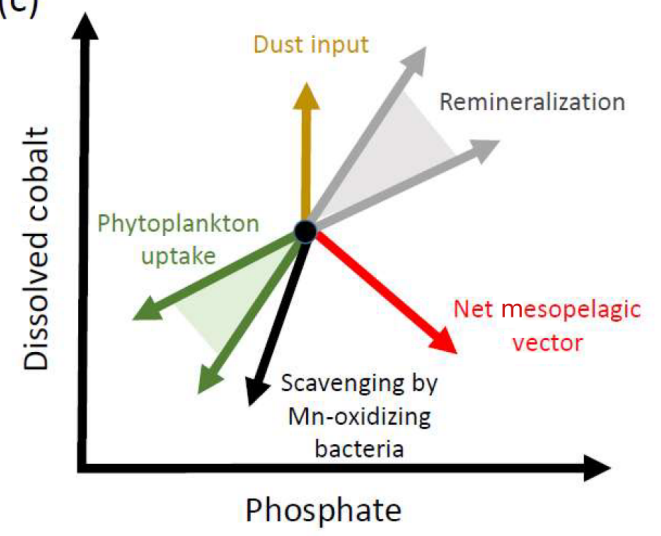

(d)

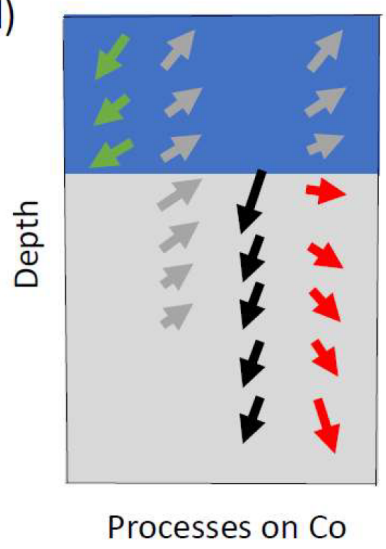

Figure 10. Vector addition demonstrating how negative $\mathrm{dCo}: \mathrm{P}$ slopes can be generated by addition of scavenging by Mn oxidation and remineralization of phytoplankton material. (a) Vector diagram representing the uptake of dissolved cobalt and phosphorus into particulate Co and $\mathrm{P}$ for photosynthetic and manganese co-oxidation processes. These vectors were generated using the measured $p$ Co and $p \mathrm{P}$ from Go-Flo bottle samples ( 67 and $136 \mathrm{~m}$ ) for the upper water column and McLane pump samples for deeper values (420 and $3000 \mathrm{~m}$ ) at Station USGT1118. Southwest negative vectors portray the uptake into particles at each depth, while a northeast grey vector portrays remineralization releasing $\mathrm{Co}$ and $\mathrm{P}$ back to the dissolved phase. (b) Example addition of Mn oxidation vector and phytoplankton remineralization that results in a negative vector as observed throughout the intermediate depths in Figs. 3-6. (c) Idealized version of vector schematic, including the net mesopelagic vector. (d) Idealized relative influence of processes on the dissolved distributions of cobalt and phosphate, using the same color scheme as (b) and (c) and the euphotic zone in blue and mesopelagic in grey. The net vectors summing the influence of all processes are on the far right and are consistent with the shift from positive to negative dCo: $\mathrm{P}$ slopes with depth calculated in Fig. 3.

biomass and Mn oxidation were calculated using measured $p \mathrm{Co}$ and $p \mathrm{P}$ from Go-Flo bottle samples for the upper water column and McLane pump samples for deeper values at Station USGT11-18 (Fig. 10a). These mesopelagic and deep Co stoichiometric values were relatively consistent across the North Atlantic Basin as shown in aggregate particle concentrations (Fig. 11a-b; McLane pump samples) and as ratios (Fig. 11c-d), with $p \mathrm{Co}: p \mathrm{Mn}$ ratio of $0.013 \pm 0.002 \mathrm{M}: \mathrm{M}$ and a $p \mathrm{Co}: p \mathrm{P}$ ratio of $1840+640 \mu \mathrm{M}: \mathrm{M}(>400 \mathrm{~m}$; excluding the North American shelf and nepheloid layers, $n=129)$. Notably, these deep $p \mathrm{Co}: p \mathrm{P}$ stoichiometries were consid- erably higher than the dissolved and particulate stoichiometries associated with the euphotic zone likely due to the accumulation of Co within Mn oxide phases, with cobalt being $\sim 1 \%$ the molar abundance of manganese in these deep particles consistent with it being a minor component of the manganese oxide phase. Lithogenic corrections included here for $p$ Co and previously described for both $p \mathrm{Co}$ and $p \mathrm{P}$ (Ohnemus and Lam, 2015) show that these elements had minor lithogenic contributions in the North Atlantic particularly in the near surface and typically being a minority contribution at deeper depths, even in the heavily impacted North Atlantic 
region (Fig. 11a, c, e). While the vector addition exercise is a comparison of two different filter pore sizes that were used in order to capture ratios for each depth region as described in "Materials and methods" $(0.2$ vs. $0.8 \mu \mathrm{m}$ in bottle versus pump particles), it is clear from Fig. 11c that even within the pump particulate dataset the $p \mathrm{Co}: p \mathrm{P}$ decreases dramatically towards the surface. Also, this deep $p \mathrm{Co}: p \mathrm{Mn}$ ratio was much lower than the $0.1-0.4(\mathrm{M}: \mathrm{M})$ ratio observed in the photic zone due to opposing trends of increased $p$ Co due to biological use and decreased $p \mathrm{Mn}$ due to photoreduction of Mn oxides and limited biological use.

Using these representative particulate values, the addition of example $\mathrm{Mn}$ oxide and remineralization vectors was able to reproduce the southeast negative slope vectors found throughout the profile-based regression analysis in the mesopelagic ocean (Fig. 10b versus Figs. 3b, g, and 4a, d). Note that the vector magnitudes were chosen for demonstration purposes here (2-fold for Mn oxidation, 1/5 for remineralization to allow for attenuation of the remineralization flux at depth), but in the water column one can envision a gradual transition between these two vectors (as visualized in schematic Fig. 10d): from remineralization dominating at the surface and Mn oxidation dominating at depth (note that uptake is not included since it withdraws from the dissolved phase while remineralization adds to it). This trend can also be summarized by Eq. (1), where the balance shifts from being dominated by the combined uptake and remineralization terms $(-\rho+$ remin $)$ in the upper water column to being dominated by scavenging removal term (Scav), which transitions with increasing depth as sinking organic matter is depleted by remineralization. This scenario is consistent with the range in observed slopes, where the negative scavenging regressions tended to increase in steepness with depth (Fig. 3d, i), as well as in the vector diagrams (Fig. 4a, d) and histogram distributions of frequency of dCo: P slopes (Fig. 4b, e).

$\frac{\mathrm{dCo}}{\mathrm{d} t}=(-\rho+$ remin $)-\mathrm{Scav}+$ diffusion

Hence we interpret these negative $\mathrm{dCo}: \mathrm{P}$ relationships as evidence of an increased influence of the scavenging removal process below the euphotic zone within each water mass. The placement of these negative slope regions in Co: $\mathrm{P}$ space is also consistent with the "cobalt curl" away from the $\mathrm{Co}: \mathrm{P}$ positive linear relationship that is common in the upper water column (see Sect. 3.1 above) that we have previous discussed (Noble et al., 2008; Saito et al., 2010). Implicit in this discussion is that the Mn oxide solid (microbial) phases are not subject to a significant extent of grazing or viral lysis that would release their constituents back to the dissolved phase, effectively creating a "one-way" trip for $\mathrm{dCo}$ into the particulate phase. While little is known about mesopelagic grazing processes, these data appear to be consistent with a net transport into the particulate phase, with no evidence for a north or northwest Mn oxide remineralization vector. These scavenging signals co-occurred with distinct water masses identified by OMPA analysis (optimum multiparameter analysis), implying that these scavenging processes are being integrated on decadal-to-century timescales of deepwater circulation processes within the ocean interior (Noble et al., 2017). Specifically, negative slope water masses were found to be in the Denmark Strait Overflow Water/Antarctic Bottom Water/Iceland Scotland Overflow Water (DSOW/AABW/ISOW) and classical Labrador Seawater (CLSW; Fig. 2) water masses both of which have long deepwater transit times (Jenkins et al., 2015).

One interesting aspect of these analyses was the high degree of depth and spatial variability of the $\mathrm{dCo}: \mathrm{P}$ relationships. In particular, there were regions of positive and negative $\mathrm{Co}: \mathrm{P}$ relationships vertically interspersed within numerous individual vertical profiles (Figs. 5-6; e.g., stations USGT10 9-11). The presence of water masses with positive $\mathrm{dCo}$ : P slopes well below the photic zone was also intriguing. This variability is typically found below the "cobalt-cline" and continues into the deep ocean, and can be attributed to temporal variability in export and remineralization and/or the horizontal advection and interweaving of remineralization signals within water masses in the vertical profile. Alternatively, if scavenging processes were to be reduced in a parcel of water for some reason, a remineralization signal could emerge, reflecting a shift in the balance of (vector) contributions. There is limited understanding regarding the controls on Mn oxidation, and hence it is difficult to imagine a mechanism for repression of scavenging at this time, although presumably Mn oxidation microbial activity is coupled to organic matter flux and hence its overall contribution would also dissipate with depth. It may be possible to use this profile-based regression analysis of $\mathrm{dCo}$ and $\mathrm{P}$ to generate an ability to detect spatial and temporal variability in deep export and remineralization events by their deep positive $\mathrm{Co}: \mathrm{P}$ relationships, if background scavenging rates could be constrained.

Analysis of specific vertical profiles of the particulate Co and $\mathrm{Mn}$ data provides further evidence for Co scavenging in the mesopelagic, and implicates manganese oxides as the responsible phase and for the transitioning of major processes with depth (Fig. 12). Comparing the dissolved and particulate phases of example vertical profiles in the eastern North Atlantic at stations 7 and 10 (USGS-2010), distinct zones of correlations were observed between $\mathrm{dCo}, \mathrm{PO}_{4}^{3-}$, $p \mathrm{Co}$, and $p \mathrm{Mn}$, above and below the $400 \mathrm{~m}$ depth horizon (Fig. 12a, g). The upper ocean showed a linear correlation of dissolved cobalt with phosphate (Fig. 12b and h, black symbols), indicative of phytoplankton uptake and remineralization of sinking material as described above. Below the $400 \mathrm{~m}$, a correlation between particulate Co and particulate Mn emerged, consistent with the scavenging process influencing both elements through incorporation into the biomineral manganese oxide (Fig. 12c and i, red symbols). For Station GT10-07, $p \mathrm{Mn}$ and $p$ Co showed this linear relationship throughout the deep ocean (from 400 to $4500 \mathrm{~m}$ ), but with 

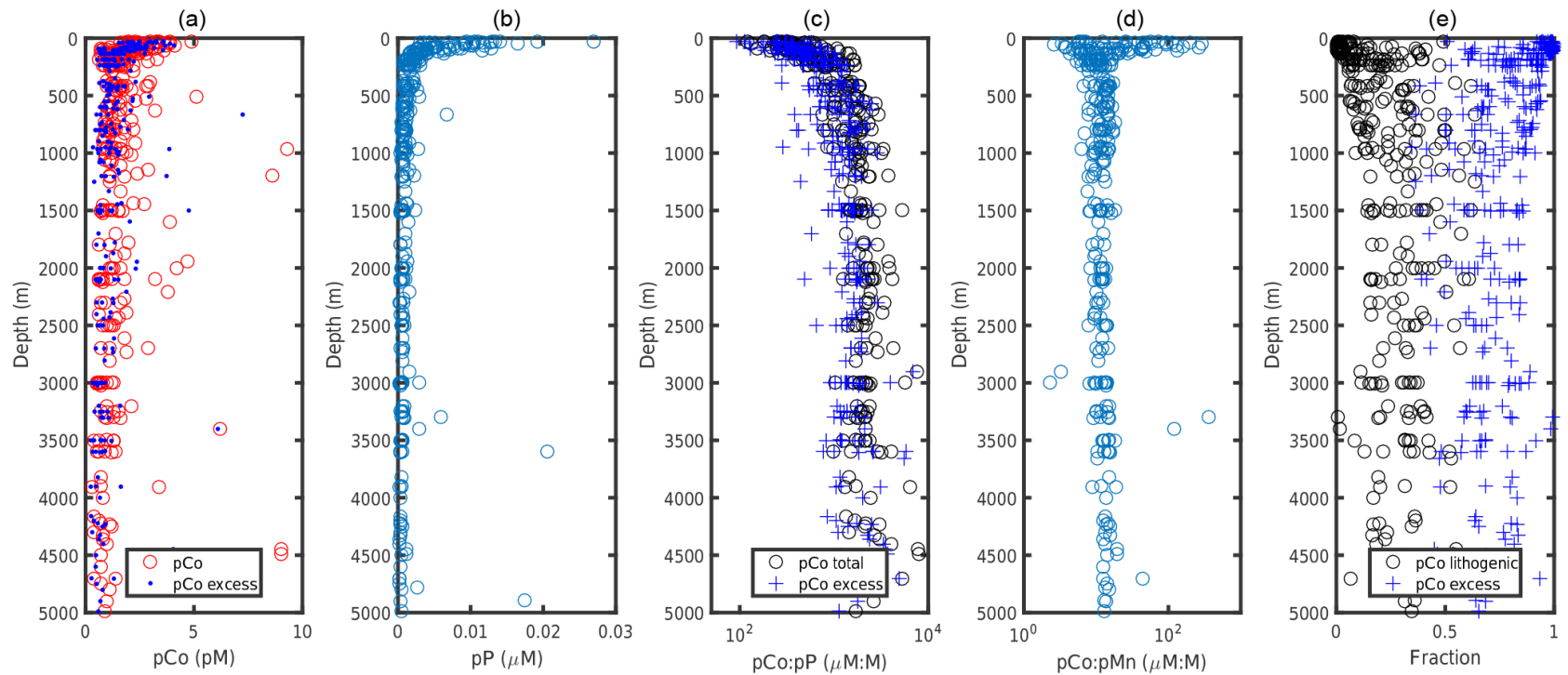

Figure 11. Full depth distributions of (a) particulate cobalt ( $p$ Co), (b) phosphorus $(p \mathrm{P})$, (c) ratios of $p$ Co: $p \mathrm{P}$ (inset $0-500 \mathrm{~m}$ depth), (d) ratios of $p \mathrm{Co}$ and particulate manganese $(p \mathrm{Co}: p \mathrm{Mn})$, and (e) the fraction of lithogenic and excess cobalt from the North Atlantic zonal GA03 section (McLane pump 0.8-51 $\mu \mathrm{m}$ filter samples; data from Ohnemus and Lam, 2015).

absolute values of both particulate metals decreasing with depth implying more active Mn oxide formation in the upper mesopelagic (Fig. 12c, f). An inverted L-shaped relationship was observed in some cases between both $p \mathrm{Mn}$ and $p \mathrm{P}$, as well as $p$ Co and $p \mathrm{P}$ (Fig. 12d, e, k) due to deeper particles having higher metals associated with the Mn oxide phase and lower phosphate than euphotic biogenic particles. These observations can be generalized across the North Atlantic GA03/3_e section by comparison of particulate Co, Mn, and $\mathrm{P}$ and applying this $400 \mathrm{~m}$ horizon. Correlations of $p \mathrm{Co}$ with both $p \mathrm{Mn}$ and $p \mathrm{P}$ were observed below $400 \mathrm{~m}$ (Fig. 13; $r^{2}$ 0.81 and 0.47 ), with enriched $p \mathrm{Co}: p \mathrm{P}$ relative to the shallower $<400 \mathrm{~m}$ zone consistent with its accumulation in microbial manganese-oxidizing bacteria.

Together, these dissolved and particulate datasets demonstrate the overall nature of the major competing processes on cobalt distributions, where the processes of phytoplankton uptake and remineralization dominate in the euphotic zone and just below it, versus the scavenging process that takes precedence as the remineralization signal subsides, as shown in schematic Fig. 10d. The biological pump processes dominate in the upper water column but should attenuate rapidly in the mesopelagic comparable to the power law decay of carbon remineralization as described by Martin et al. (1987), and the export flux contribution is likely to vary geographically due to the episodic nature of phytoplankton blooms. Simultaneously, the contribution of scavenging likely increases below the upper euphotic zone as light subsides and photoreduction of manganese oxides ceases (Sunda and Huntsman, 1994), yet little is known about what might regulate the extent of bacterially catalyzed manganese oxi- dation, but could include bacterial activity, organic matter, manganese, $\mathrm{pH}$, and/or dissolved oxygen availability (Johnson et al., 1996; Morgan, 2005; Tebo et al., 1984). Indeed, Moffett and Ho (1996) observed a large dynamic range of 300 -fold difference in manganese oxidation rates, as a percentage of tracer oxidized per hour, between a coastal estuary and the oligotrophic ocean. The relative contribution of these two processes should invert near the maximum of the dissolved cobalt profile, contributing to its characteristic sharp peaks at these intermediate depths (Fig. 3). With this competition between vertical processes, the depth of the cobalt maximum could vary with the extent of vertical export and Mn oxide production. The balancing act between these two major processes is apparent in the variability of individual profiles, demonstrating the complex hybrid nature of the dissolved cobalt profile. Scavenging of dCo appears to be a critical process in controlling the inventory of cobalt in the oceans, and this topic, including the estimate of overall scavenging influences during horizontal advection through ocean basins, is further explored in Hawco et al. (2016).

\subsection{Ocean sections of $\mathrm{Co}^{*}$ and $\mathrm{dCo}: \mathrm{P}$ slopes}

Two derived values of dissolved cobalt were calculated for the North Atlantic Ocean GA03 section to provide largescale assessment of cobalt's properties and comparison with dCo and phosphate distributions (Fig. 14a-d). The first of these is the $\mathrm{dCo}: \mathrm{P}$ slope value calculated by the profileregression approach described above (representing the midpoint of linear regressions for successive groupings of five depth points in each vertical profile; Fig. 14c). The second of these is a "nutrient-star" calculation similar to that used 

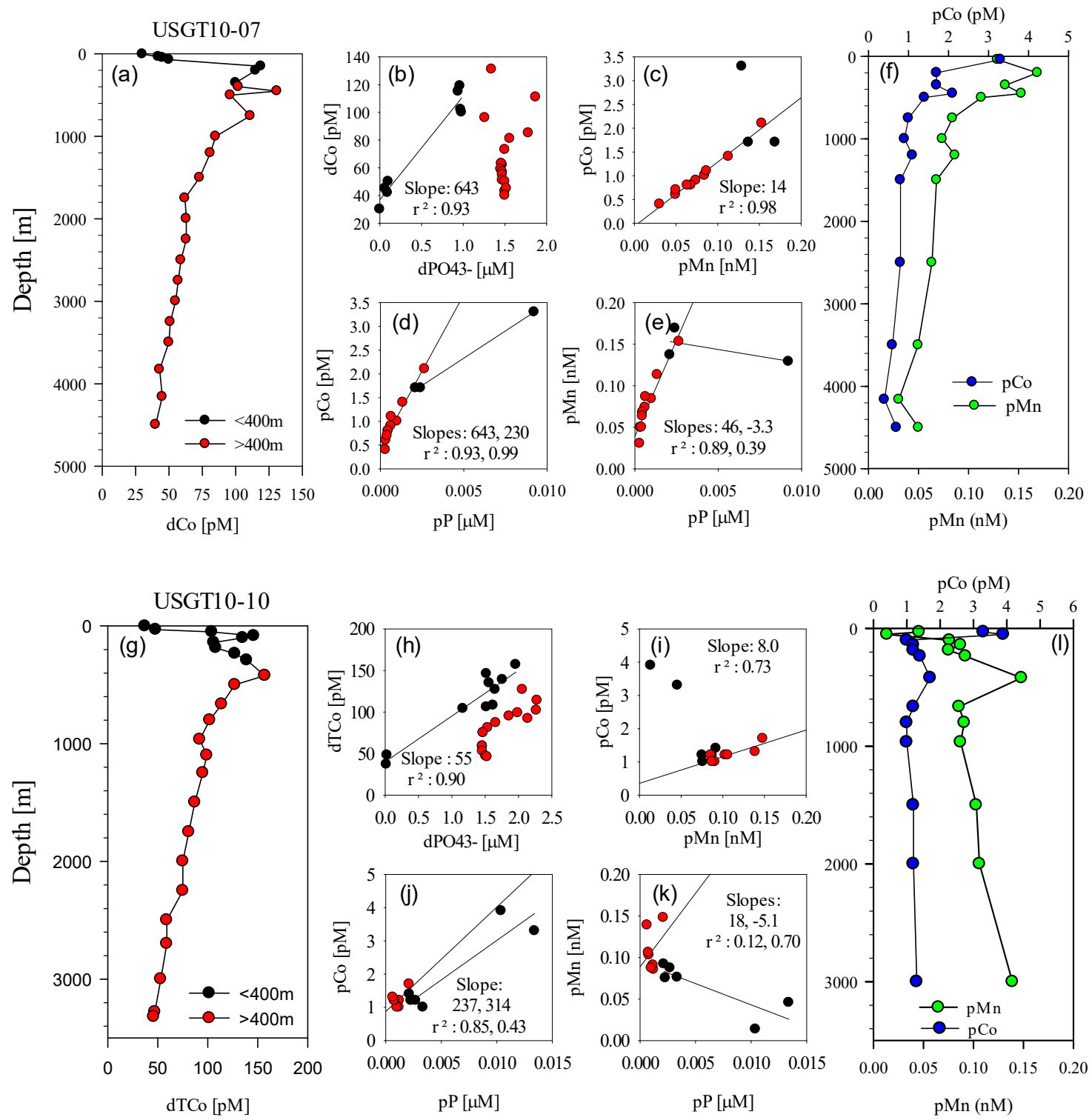

Figure 12. Dissolved and particulate Co and associations with $P$ and Mn from selected stations (USGT10-7 and 10-10) from the GA03/3_e expedition and comparisons of dissolved Co and dissolved phosphate (b, h), particulate Co and particulate Mn (c, i), particulate Co and particulate $\mathrm{P}(\mathbf{d}, \mathbf{j})$, and particulate $\mathrm{Mn}$ and particulate $\mathrm{P}(\mathbf{e}, \mathbf{k})$ are shown. dCo and phosphate. dCo and phosphate showed linear relationships above $400 \mathrm{~m}(\mathbf{b}, \mathbf{h})$, while $p$ Co and $p \mathrm{Mn}$ were related below $400 \mathrm{~m}(\mathbf{c}, \mathbf{i})$, consistent with a transition between uptake and remineralization dominance $(<400 \mathrm{~m})$ and scavenging by manganese oxides $(>400 \mathrm{~m})$, and the profile vertical structure (a, g).

originally for nitrogen and applied to other nutrients (Gruber and Sarmiento, 1997; Deutsch et al., 2001; Fig. 14d). Here Co* represents a deviation from "Redfield" stoichiometric use, and was calculated using Eq. (2):

$\mathrm{Co} *=\mathrm{dCo}-Q \mathrm{P}$,

where $Q$ represents the assumed Co:P quota value of $237 \mu \mathrm{mol}: \mathrm{mol}$, which was used based on aggregate $p \mathrm{Co}: p \mathrm{P}$ ratio in the upper $400 \mathrm{~m}$ (pump dataset), and an intercept of zero was assumed implying a basal requirement in life for both Co and P. Both of these assumptions are debatable given cobalt's unusual biochemistry as described above: the basal $Q$ value is likely subject to the environmental conditions of each region, especially the phosphorus content as described above, but appears reasonable compared to basinwide least squares average of 150 for picoplankton (Twining et al., 2015). Obviously selecting a "Redfield" cobalt $Q$ value is not trivial, since the stoichiometry of $\mathrm{Co}: \mathrm{P}$ as described above can be highly variable; hence, this current effort in developing a $\mathrm{Co}^{*}$ equation should be considered preliminary.

In spite of these caveats, the resulting $\mathrm{Co}^{*}$ section was surprising in its smoothness with gradual transitions from the 

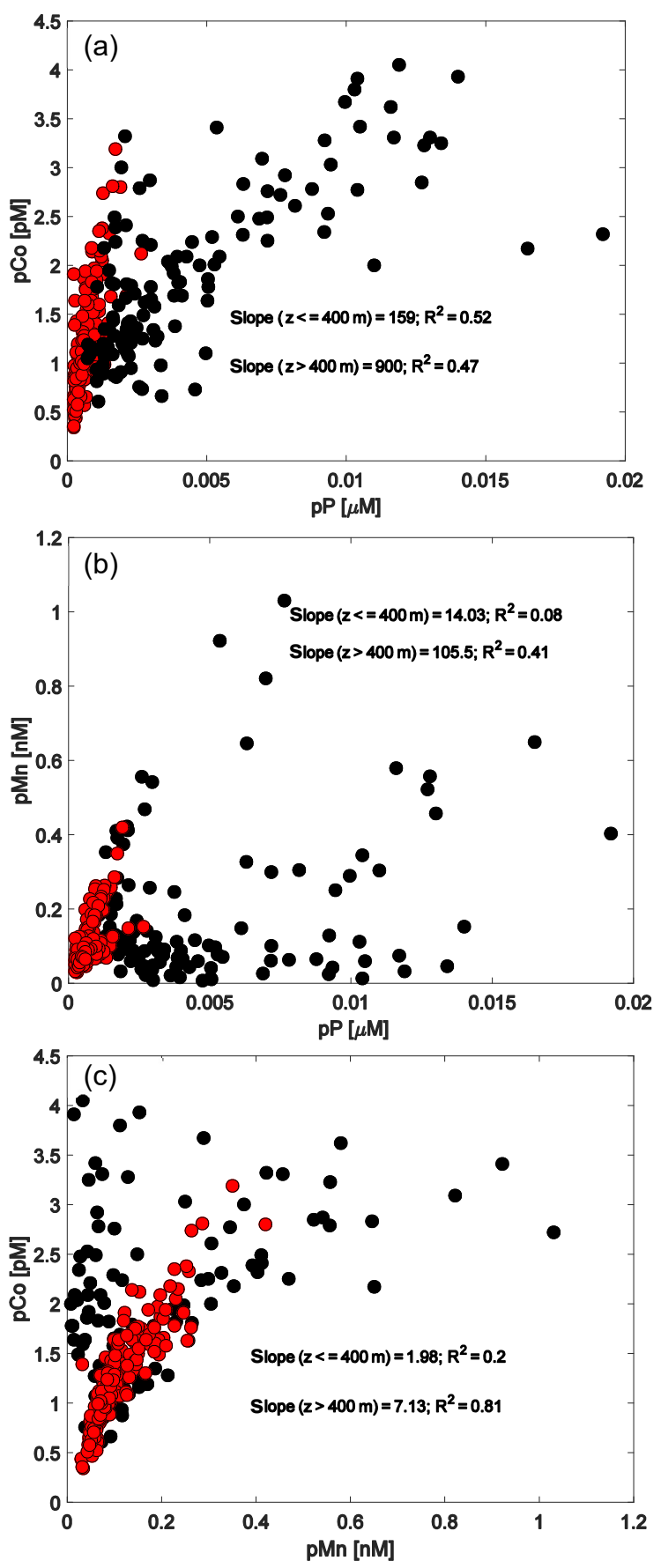

Figure 13. Comparison of pump particulate $\mathrm{Co}, \mathrm{Mn}$, and $\mathrm{P}$ in the North Atlantic (GA03/3_e) above (black symbols) and below (red symbols) $400 \mathrm{~m}$ depth as evidence for scavenging of cobalt. (a) Higher $p \mathrm{Co}: p \mathrm{P}$ relationships are observed $(160 \mu \mathrm{mol}: \mathrm{mol}$ $\mathrm{Co}: \mathrm{P}$ ) below $400 \mathrm{~m}$ likely due to the prevalence of Co incorporation into $\mathrm{Mn}$ oxides as demonstrated by the high $p \mathrm{Mn}: p \mathrm{P}(\mathbf{b})$ and linear relationship between $p \mathrm{Co}$ and $p \mathrm{Mn}$ (c) observed below $400 \mathrm{~m}$. surface to deep ocean for an element with such a small and dynamic inventory. Notable features include low $\mathrm{Co}^{*}$ values in the mesopelagic and deep ocean due to scavenging, with the oxygen minimum zone (OMZ) region being lowest despite being the location of a major Co plume. In particular, the $\mathrm{Co}^{*}$ deficit observed within the subsurface represents a useful indicator for the integrated influence of cobalt scavenging. One can consider that during periods of ocean anoxia or suboxia, these negative $\mathrm{Co}^{*}$ regions in the ocean interior would likely be replaced by higher $\mathrm{dCo}$ inventories and associated positive $\mathrm{Co}^{*}$ values as the Co scavenging process is diminished due to lack of oxygen, as has been predicted for the Neoproterozoic era (Saito et al., 2003) and observed in modern OMZs (Hawco et al., 2016; Noble et al., 2012, 2017). The selection of this moderate $Q$ value results in $\mathrm{Co}^{*}$ values that were considerably in excess of unity in the upper water column. Obviously any shift in $Q$ would shoal or deepen these features, and hence the accelerating stoichiometries observed in the upper photic zone are problematic in deploying in a single derived $\mathrm{Co}^{*}$ field.

A sectional visualization of $\mathrm{dCo}: \mathrm{P}$ slopes was strikingly distinct from that of $\mathrm{Co}^{*}$ with a patchiness associated with distinct regions and depths. These patches were the regions of accelerating slope identified in the profile-based analysis described earlier. There were several salient trends apparent in this section. First, strong Co scavenging at the hydrothermal vents was readily apparent, caused by high near-field cobalt concentrations being subjected to rapid losses without comparable (stoichiometric) losses in phosphate. Second, the enhanced remineralization (positive) slopes, described briefly above, were apparent below the OMZ of the Mauritanian Upwelling. This intriguing observation implies that material sinking through the OMZ was prevented from degrading rapidly due to low oxygen, but below the OMZ remineralization resumed. Alternatively, it could imply that the remineralization of biomass from within the OMZ has higher $p \mathrm{Co}: p \mathrm{P}$ quotas, as observed recently in the US GEOTRACES eastern tropical zonal transect (Ohnemus et al., 2017), resulting in an acceleration of $\mathrm{Co}: \mathrm{P}$ in the dissolved phase. The archaea known to inhabit the ocean interior have high abundances of $\mathrm{B}_{12}$ biosynthetic proteins, supporting this notion of a deep biological Co demand and potential export (Santoro et al., 2015). Finally, the elevated slopes observed at Station 11-06 on the North American Atlantic shelf could indicate either subducted surface waters with a highly elevated Co: $\mathrm{P}$ stoichiometry or evidence of remineralization of a prior export event.

\section{Conclusions and implications}

In this study the relationships of dissolved and particulate cobalt relative to phosphorus on zonal sections of the North and South Atlantic were investigated and their implications for the ecological stoichiometry and biogeochem- 

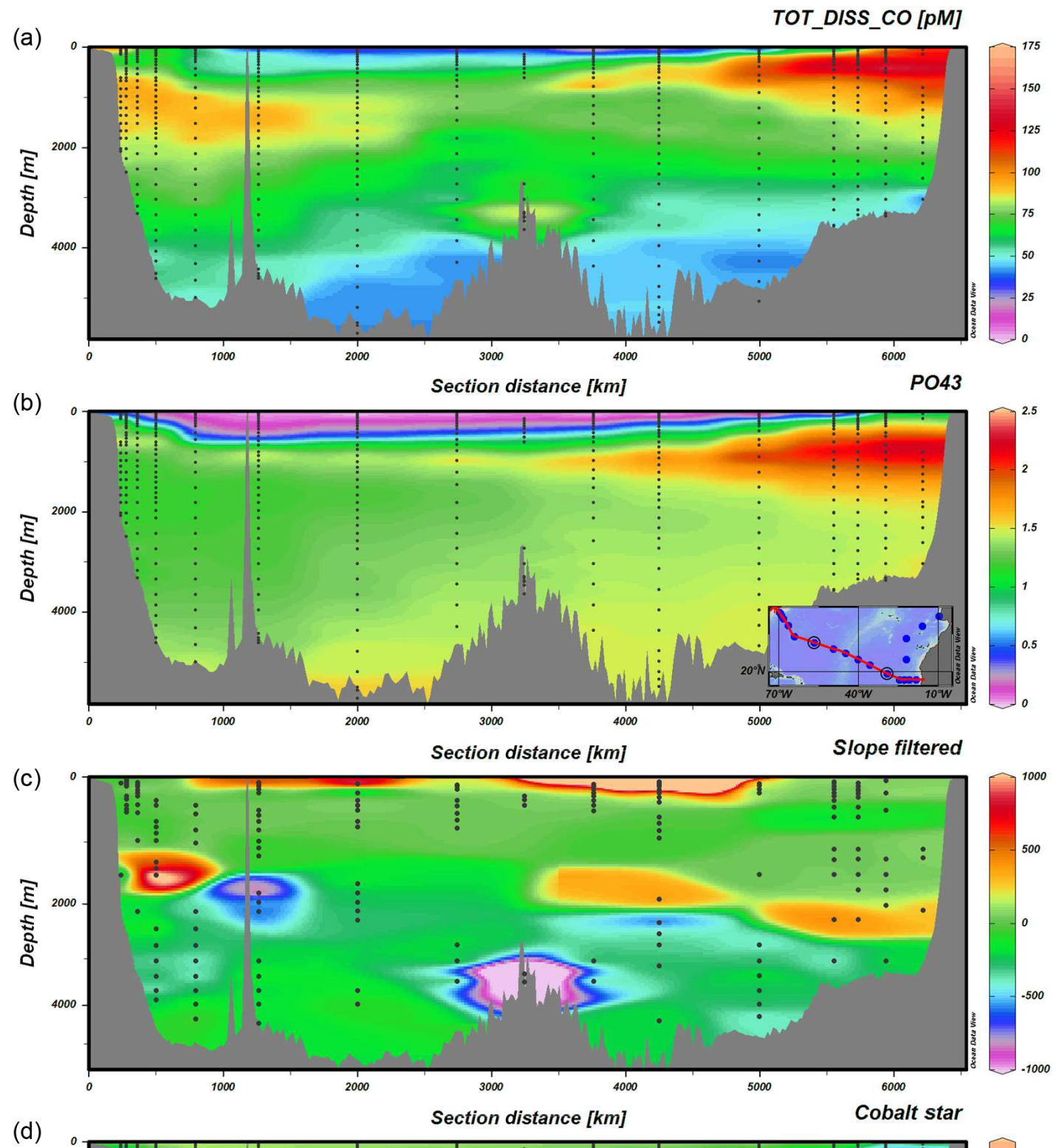

$(\mathrm{d})$

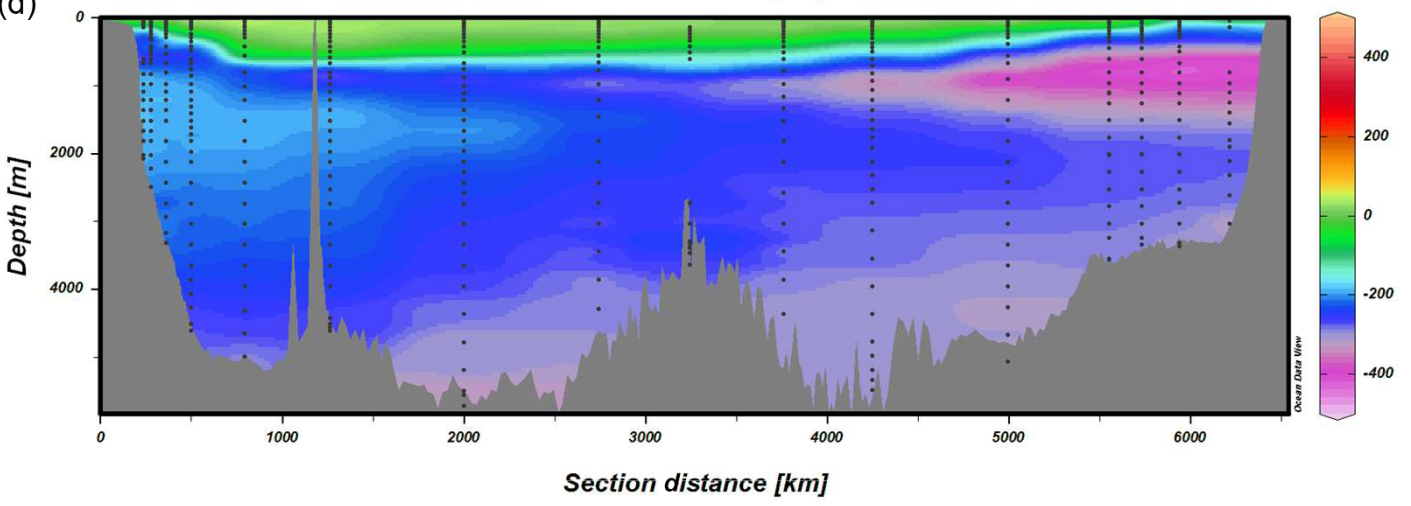

Figure 14. Comparison of derived variables related to dissolved cobalt and phosphorus inventories in the zonal portion of the US North Atlantic transect (GA03). Ocean sections of (a) dissolved cobalt (pM), (b) phosphate $(\mu \mathrm{M})$, (c) dCo: P slopes $(r \geq|0.7|)$, and (d) Co* (with a Co: $\mathrm{P}$ stoichiometry of $237 \mu \mathrm{mol} \mathrm{mol}{ }^{-1}$ based on the aggregate $p \mathrm{Co}: p \mathrm{P}$ ratio in the upper $\left.400 \mathrm{~m}\right)$. 
istry of cobalt were described. In particular, the finer-scale structure of $\mathrm{dCo}: \mathrm{P}$ relationships was characterized by use of linear regressions on small subsets of data within each vertical profile on the sections. The most prominent observations were that the dissolved cobalt stoichiometry varied by more than an order of magnitude and that the sign of the relationships switched from positive to negative in the mesopelagic. In the upper photic zone, an acceleration of these stoichiometries was observed in the dissolved phase due to a combined influence of phosphate scarcity and its biochemical influence on cellular $\mathrm{P}$ use, as well as increases in Co use upon $\mathrm{Zn}$ depletion and within the cyanobacterial alkaline phosphatase metalloenzyme, as supported by metaproteomic data. In the mesopelagic, the observance of negative $\mathrm{dCo}$ : P relationships coincided with adherence of the particulate cobalt phase, with the particulate manganese phase providing direct evidence of the influence of manganese scavenging upon dissolved cobalt. An additional potential influence is the preferential remineralization of $\mathrm{P}$ relative to $\mathrm{Co}$, that could cause decreases in $\mathrm{Co}^{*}$, although the contribution of this phenomenon relative to scavenging is presumably small. The biogeochemical cycling of cobalt is interesting when compared to Alfred Redfield's early consideration of the connection between dissolved and particulate phases through oceanic "biochemical circulation". With the smallest inventory of any required nutritional element in the oceans and its potential for biochemical substitution, dissolved Co stoichiometries found in the oceans appear to be among the most dynamic of any element used by life. As a result, the coherence in stoichiometry between dissolved and particulate phases appears less of a duet as for other elements $(\mathrm{N}, \mathrm{P}$, $\mathrm{Cd}, \mathrm{Zn}$ ) than a tug-of-war for control of processes.

Data availability. The datasets used for analysis in this study were first described in Noble et al. $(2012,2017)$ and the datasets are available at Biological and Chemical Oceanography Data Management Office (BCO-DMO): http://www.bco-dmo.org/dataset/ 642974 (GEOTRACES NAZT GA03) and http://www.bco-dmo. org/dataset/3233 (CoFeMUG GEOTRACES GAc01).

Competing interests. The authors declare that they have no conflict of interest.

Acknowledgements. This work was funded by the National Science Foundation as part of the US GEOTRACES North Atlantic Zonal Transect program under grants OCE-0928414 and OCE-1435056 (to Mak A. Saito), OCE-0928289 (to Benjamin S. Twining), OCE-0963026 (to Phoebe Lam) and support from the Gordon and Betty Moore Foundation (3782 to Mak A. Saito). We are indebted to the captain and crew of the R/V Knorr for their exemplary support on both GA03 and GAc01 expeditions, as well as chief scientists Bill Jenkins, Ed Boyle, and Greg Cutter and the dissolved and particulate sampling teams. We also appreciate the support of the captain and crew of the R/V Atlantic Explorer, as well as support from the BATS group for assistance with McLane protein profile sampling. We thank Rachel Shelley, Marie Boye, and Gabriel Dulaquais for their helpful reviews that improved this paper.

Edited by: Gerhard Herndl

Reviewed by: Rachel Shelley and Marie Boye

\section{References}

Aguirre, J. D., Clark, H. M., McIlvin, M., Vazquez, C., Palmere, S. L., Grab, D. J., Seshu, J., Hart, P. J., Saito, M., and Culotta, V. C.: A manganese-rich environment supports superoxide dismutase activity in a Lyme disease pathogen, Borrelia burgdorferi, J. Biol. Chem., 288, 8468-8478, 2013.

Ahlgren, N. A., Noble, A., Patton, A. P., Roache-Johnson, K., Jackson, L., Robinson, D., McKay, C., Moore, L. R., Saito, M. A., and Rocap, G.: The unique trace metal and mixed layer conditions of the Costa Rica upwelling dome support a distinct and dense community of Synechococcus, Limnol. Oceanogr., 59, 2166-2184, 2014.

Anderson, T. R. and Pondaven, P.: Non-redfield carbon and nitrogen cycling in the Sargasso Sea: pelagic imbalances and export flux, Deep-Sea Res. Pt. I, 50, 573-591, 2003.

Arrigo, K. R., Robinson, D. H., Worthen, D. L., Dunbar, R. B., DiTullio, G. R., VanWoert, M., and Lizotte, M. P.: Phytoplankton Community Structure and the Drawdown of Nutrients and $\mathrm{CO}_{2}$ in the Southern Ocean, Science, 283, 365-367, 1999.

Baars, O. and Croot, P. L.: Dissolved cobalt speciation and reactivity in the eastern tropical North Atlantic, Mar. Chem., 173, 310-319, 2015.

Bertilsson, S., Berglund, O., Karl, D. M., and Chisholm, S. W.: Elemental composition of marine Prochlorococcus and Synechococcus: Implications for ecological stoichiometry of the sea, Limnol. Oceanogr., 48, 1721-1731, 2003.

Bishop, J. K., Lam, P. J., and Wood, T. J.: Getting good particles: Accurate sampling of particles by large volume in-situ filtration, Limnol. Oceanogr.-Meth., 10, 681-710, 2012.

Bown, J., Boye, M., Baker, A., Duvieilbourg, E., Lacan, F., Le Moigne, F., Planchon, F., Speich, S., and Nelson, D. M.: The biogeochemical cycle of dissolved cobalt in the Atlantic and the Southern Ocean south off the coast of South Africa, Mar. Chem., 126, 193-206, 2011.

Bown, J., Boye, M., and Nelson, D. M.: New insights on the role of organic speciation in the biogeochemical cycle of dissolved cobalt in the southeastern Atlantic and the Southern Ocean, Biogeosciences, 9, 2719-2736, https://doi.org/10.5194/bg-9-27192012, 2012.

Boyle, E. A.: Cd: chemical tracer of deep-water paleooceanography, Paleooceanogr., 3, 471-489, 1988.

Boyle, E. A., Sclater, F. R., and Edmond, J. M.: On the marine geochemistry of cadmium, Nature, 263, 42-44, 1976.

Bruland, K. W.: Complexation of cadmium by natural organic ligands in the central North Pacific, Limnol. Oceanogr., 37, 10081016, 1992.

Bruland, K. W.: Complexation of zinc by natural organic ligands in the central North Pacific, Limnol. Oceanogr., 34, 269-285, 1989. 
Bruland, K. W. and Franks, R. P.: $\mathrm{Mn}, \mathrm{Ni}, \mathrm{Cu}, \mathrm{Zn}$ and $\mathrm{Cd}$ in the western North Atlantic, in: Trace Metals in Seawater NATO Conference Series 4, Plenum, 1983.

Bruland, K. W. and Lohan, M. C.: Controls of Trace Metals in Seawater, in: Treatise on Geochemistry, edited by: Turekian, K. K. and Holland, H. D., Elsevier Science Ltd, Cambridge, 2003.

Buck, K. N., Sohst, B., and Sedwick, P. N.: The organic complexation of dissolved iron along the U.S. GEOTRACES (GA03) North Atlantic Section, Deep-Sea Res. Pt. II, 116, 152-165, 2015.

Cavender-Bares, K. K., Mann, E. L., Chisholm, S. W., Ondrusek, M. E., and Bidigare, R. R.: Differential Response of equatorial Pacific phytoplankton to iron fertilization, Limnol. Oceanogr., 44, 237-246, 1999.

Conway, T. M. and John, S. G.: Biogeochemical cycling of cadmium isotopes along a high-resolution section through the North Atlantic Ocean, Geochim. Cosmochim. Ac., 148, 269-283, 2015.

Conway, T. M. and John, S. G.: The biogeochemical cycling of zinc and zinc isotopes in the North Atlantic Ocean, Global Biogeochem. Cy., 28, 1111-1128, 2014.

Conway, T. M., Rosenberg, A. D., Adkins, J. F., and John, S. G.: A new method for precise determination of iron, zinc and cadmium stable isotope ratios in seawater by double-spike mass spectrometry, Anal. Chim. Acta, 793, 44-52, 2013.

Cowen, J. P. and Bruland, K. W.: Metal deposits associated with bacteria: implications for $\mathrm{Fe}$ and $\mathrm{Mn}$ marine biogeochemistry, Deep-Sea Res., 32, 253-272, 1985.

Cox, A. D. and Saito, M. A.: Proteomic responses of oceanic Synechococcus WH8102 to phosphate and zinc scarcity and cadmium additions, Front. Microbiol., 4, 387, https://doi.org/10.3389/fmicb.2013.00387, 2013.

Cullen, J. T., Chase, Z., Coale, K. H., Fitzwater, S. E., and Sherrell, R. M.: Effect of iron limitation on the cadmium to phosphorus ratio of natural phytoplankton assemblages from the Southern Ocean, Limnol. Oceanogr., 48, 1079-1087, 2003.

Deutsch, C., Gruber, N., Key, R. M., Sarmiento, J. L., and Ganachaud, A.: Denitrification and N2 Fixation in the Pacific Ocean, Glob. Biogeochem. Cy., 15, 483-506, 2001.

Duhamel, S., Dyhrman, S. T., and Karl, D. M.: Alkaline phosphatase activity and regulation in the North Pacific Subtropical Gyre, Limnol. Oceanogr., 55, 1414-1425, 2010.

Dulaquais, G., Boye, M., Middag, R., Owens, S., Puigcorbe, V., Buesseler, K., Masqué, P., Baar, H. J., and Carton, X.: Contrasting biogeochemical cycles of cobalt in the surface western Atlantic Ocean, Global Biogeochem. Cy., 28, 1387-1412, 2014a.

Dulaquais, G., Boye, M., Rijkenberg, M. J. A., and Carton, X.: Physical and remineralization processes govern the cobalt distribution in the deep western Atlantic Ocean, Biogeosciences, 11, 1561-1580, https://doi.org/10.5194/bg-11-1561-2014, 2014b.

Dyhrman, S. T., Jenkins, B. D., Rynearson, T. A., Saito, M. A., Mercier, M. L., Alexander, H., Whitney, L. P., Drzewianowski, A., Bulygin, V. V., Bertrand, E. M., Wu, Z., BenitezNelson, C., and Heithoff, A.: The Transcriptome and Proteome of the Diatom Thalassiosira pseudonana Reveal a Diverse Phosphorus Stress Response, PLoS ONE, 7, e33768, https://doi.org/10.1371/journal.pone.0033768, 2012.

Dyhrman, S. T., Webb, E. A., Anderson, D. M., Moffett, J. W., and Waterbury, J. B.: Cell-specific detection of phosphate stress in Trichodesmium from the Western North Atlantic, Limnol Oceanogr., 47, 1832-1836, 2002.

Ellwood, M. J.: Zinc and cadmium speciation in subantarctic waters east of New Zealand, Mar. Chem., 87, 37-58, 2004.

Geotraces Group: The GEOTRACES intermediate data product 2014, Mar. Chem., 177, 1-8, 2015.

Glover, D. M., Jenkins, W. J., and Doney, S. C.: Modeling methods for marine science, Cambridge University Press, 2011.

Grob, C., Ostrowski, M., Holland, R. J., Heldal, M., Norland, S., Erichsen, E. S., Blindauer, C., Martin, A. P., Zubkov, M. V., and Scanlan, D. J.: Elemental composition of natural populations of key microbial groups in Atlantic waters, Environ. Microbiol., 15, 3054-3064, 2013.

Gruber, N. and Sarmiento, J. L.: Global patterns of marine nitrogen fixation and denitrification, Global Biogeochem. Cy., 11, 235266, 1997.

Hatta, M., Measures, C. I., Wu, J., Roshan, S., Fitzsimmons, J. N., Sedwick, P., and Morton, P.: An overview of dissolved Fe and Mn distributions during the 2010-2011 U.S. GEOTRACES north Atlantic cruises: GEOTRACES GA03, Deep-Sea Res. Pt. II, 116, 117-129, 2015.

Hawco, N. J., Ohnemus, D. C., Resing, J. A., Twining, B. S., and Saito, M. A.: A dissolved cobalt plume in the oxygen minimum zone of the eastern tropical South Pacific, Biogeosciences, 13, 5697-5717, https://doi.org/10.5194/bg-13-5697-2016, 2016.

Ho, T.-Y., Quigg, A., Finkel, Z. V., Milligan, A. J., Wyman, K., Falkowski, P. G., and Morel, F. M. M.: The Elemental Composition Of Some Marine Phytoplankton, J. Phycol., 39, 1145-1159, 2003.

Hughes, C. S., Foehr, S., Garfield, D. A., Furlong, E. E., Steinmetz, L. M., and Krijgsveld, J.: Ultrasensitive proteome analysis using paramagnetic bead technology, Molecul. Syst. Biol., 10, 1-14, 2014.

Jakuba, R. W., Moffett, J. W., and Dyhrman, S. T.: Evidence for the linked biogeochemical cycling of zinc, cobalt, and phosphorus in the western North Atlantic Ocean, Global Biogeochem. Cy., 22, GB4012, https://doi.org/10.1029/2007GB003119, 2008.

Jenkins, W. J., Smethie Jr, W. M., Boyle, E. A., and Cutter, G. A.: Water mass analysis for the U.S. GEOTRACES (GA03) North Atlantic sections, Deep-Sea Res. Pt. II, 116, 6-20, 2015.

Johnson, K. S., Coale, K. H., Berelson, W. M., and Gordon, R. M.: On the formation of the manganese in the oxygen minimum, Geochim. Cosmochim. Ac., 60, 1291-1299, 1996.

Kathuria, S. and Martiny, A. C.: Prevalence of a calcium-based alkaline phosphatase associated with the marine cyanobacterium Prochlorococcus and other ocean bacteria, Environ. Microbiol., 13, 74-83, 2011.

Kim, E. E. and Wyckoff, H. W.: Reaction mechanism of alkaline phosphatase based on crystal structures: two-metal ion catalysis, J. Mol. Biol., 218, 449-464, 1991.

Knauer, G. A., Martin, J. H., and Gordon, R. M.: Cobalt in northeast Pacific waters, Nature, 297, 49-51, 1982.

Lane, E. S., Semeniuk, D. M., Strzepek, R. F., Cullen, J. T., and Maldonado, M. T.: Effects of iron limitation on intracellular cadmium of cultured phytoplankton: Implications for surface dissolved cadmium to phosphate ratios, Mar. Chem., 115, 155-162, 2009. 
Lane, T. W., Saito, M. A., George, G. N., Pickering, I. J., Prince, R. C., and Morel, F. M. M.: A cadmium enzyme from a marine diatom, Nature, 435, 42, 2005.

Lee, B. and Fisher, N. S.: Microbially mediated cobalt oxidation in seawater revealed by radiotracer experiments, Limnol. Oceanogr., 38, 1593-1602, 1993.

Lee, Y. and Tebo, B.: Cobalt(II) Oxidation by the Marine Manganese(II)-Oxidizing Bacillus sp. Strain SG-1, Appl. Environ. Microbiol., 60, 2949-2957, 1994.

Mackey, K. R., Chien, C.-T., Post, A. F., Saito, M. A., and Paytan, A.: Rapid and gradual modes of aerosol trace metal dissolution in seawater, Front. Microbiol., 5, 1-11, https://doi.org/10.3389/fmicb.2014.00794, 2015.

Mahaffey, C., Reynolds, S., Davis, C. E., and Lohan, M. C.: Alkaline phosphatase activity in the subtropical ocean: insights from nutrient, dust and trace metal addition experiments, Front. Mar. Sci., 1, 1-18, https://doi.org/10.3389/fchem.2013.00025, 2014.

Mann, E. L. and Chisholm, S. W.: Iron limits the cell division rate of Prochlorococcus in the Eastern Equatorial Pacific, Limnol. Oceanogr., 45, 1067-1076, 2000.

Martin, J. H., Gordon, R. M., Fitzwater, S., and Broenkow, W. W.: VERTEX: phytoplankton/iron studies in the Gulf of Alaska., Deep-Sea Res., 36, 649-680, 1989.

Martin, J. H., Knauer, G. A., Karl, D. M., and Broenkow, W. W.: VERTEX: carbon cycling in the northeast Pacific, Deep-Sea Res., 34, 267-285, 1987.

Martiny, A. C., Pham, C. T. A., Primeau, F. W., Vrugt, J. A., Moore, J. K., Levin, S. A., and Lomas, M. W.: Strong latitudinal patterns in the elemental ratios of marine plankton and organic matter, Nat. Geosci., 6, 279-283, 2013.

Moffett, J. W. and Ho, J.: Oxidation of cobalt and manganese in seawater via a common microbially catalyzed pathway, Geochim. Cosmochim. Ac., 60, 3415-3424, 1996.

Morel, F. M. M., Reinfelder, J. R., Roberts, S. B., Chamberlain, C. P., Lee, J. G., and Yee, D.: Zinc and carbon co-limitation of marine phytoplankton, Nature, 369, 740-742, 1994.

Morgan, J. J.: Kinetics of reaction between $\mathrm{O}_{2}$ and $\mathrm{Mn}$ (II) species in aqueous solutions, Geochim. Cosmochim. Ac., 69, 35-48, 2005

Noble, A. E., Saito, M. A., Maiti, K., and Benitez-Nelson, C.: Cobalt, manganese, and iron near the Hawaiian Islands: A potential concentrating mechanism for cobalt within a cyclonic eddy and implications for the hybrid-type trace metals, Deep-Sea Res. II, 55, 1473-1490, 2008.

Noble, A. E., Lamborg, C. H., Ohnemus, D., Lam, P. J., Goepfert, T. J., Measures, C. I., Frame, C. H., Casciotti, K., DiTullio, G. R., Jennings, J., and Saito, M. A.: Basin-scale inputs of cobalt, iron, and manganese from the Benguela-Angola front into the South Atlantic Ocean, Limnol. Oceanogr., 57, 989-1010, 2012.

Noble, A. E., Ohnemus, D. C., Hawco, N. J., Lam, P. J., and Saito, M. A.: Coastal sources, sinks and strong organic complexation of dissolved cobalt within the US North Atlantic GEOTRACES transect GA03, Biogeosciences, 14, 2715-2739, https://doi.org/10.5194/bg-14-2715-2017, 2017.

Noble, A. E., Saito, M. A., Maiti, K., and Benitez-Nelson, C.: Cobalt, manganese, and iron near the Hawaiian Islands: A potential concentrating mechanism for cobalt within a cyclonic eddy and implications for the hybrid-type trace metals, Deep-Sea Res. II, 55, 1473-1490, 2008.
Noble, A. E., Saito, M. A., Moran, D. M., and Allen, A. Dissolved and particulate trace metal micronutrients under the McMurdo Sound seasonal sea ice: basal sea ice communities as a capacitor for iron, Front. Microbiol. Chem., https://doi.org/10.3389/fchem.2013.00025 2013.

Ohnemus, D. C. and Lam, P. J.: Cycling of lithogenic marine particles in the US GEOTRACES North Atlantic transect, Deep-Sea Res. Pt. II, 116, 283-302, 2015.

Ohnemus, D. C., Rauschenberg, S., Cutter, G. A., Fitzsimmons, J. N., Sherrell, R. M., and Twining, B. S.: Elevated trace metal content of prokaryotic communities associated with marine oxygen deficient zones, Limnol. Oceanogr., 62, 3-25, 2017.

Olson, R. J., Chisholm, S. W., Zettler, E. R., Altabet, M. A., and Dusenberry, J. A.: Spatial and temporal distribution of prochlorophyte picoplankyon in the North Atlantic Ocean, Deep-Sea Res., 37, 1033-1051, 1990.

Outten, C. E. and O'Halloran, T. V.: Femtomolar sensitivity of metalloregulatory Proteins Controlling Zinc Homeostasis, Science, 292, 2488-2492, 2001.

Pratt, J. M., Simpson, D. M., Doherty, M. K., Rivers, J., Gaskell, S. J., and Beynon, R. J.: Multiplexed absolute quantification for proteomics using concatenated signature peptides encoded by QconCAT genes, Nat. Protoc., 1, 1029-1043, 2006.

Redfield, A. C.: The biological control of chemical factors in the environment, Am. Sci., 46, 205-221, 1958.

Redfield, A. C., Ketchum, B. H., and Richards, F. A. (Eds.): The Influence of Organisms on the Composition of Sea-Water, Wiley, 1963.

Roberts, S., Lane, T., and Morel, F. M. M.: Carbonic anhydrase in the marine diatom Thalassiosira weissflogii (Bacillariophyceae), J. Phycol., 33, 845-850, 1997.

Rodionov, D. A., Vitreschak, A. G., Mironov, A. A., and Gelfand, M. S.: Comparative Genomics of the Vitamin $\mathrm{B}_{12}$ Metabolism and Regulation in Prokaryotes, J. Biol. Chem., 278, 4114841159, 2003

Saito, M. A., Moffett, J. W., and DiTullio, G.: Cobalt and Nickel in the Peru Upwelling Region: a Major Flux of Cobalt Utilized as a Micronutrient, Global Biogeochem. Cy., 18, https://doi.org/10.1029/2003GB002216, 2004.

Saito, M. A., Dorsk, A., Post, A. F., McIlvin, M., Rappé, M. S., DiTullio, G., and Moran, D.: Needles in the Blue Sea: Sub-Species Specificity in Targeted Protein Biomarker Analyses Within the Vast Oceanic Microbial Metaproteome, Proteomics, 15, 35213531, 2015.

Saito, M. A. and Goepfert, T. J.: Zinc-cobalt colimitation in Phaeocystis antarctica, Limnol. Oceanogr., 53, 266-275, 2008.

Saito, M. A., Goepfert, T. J., Noble, A. E., Bertrand, E. M., Sedwick, P. N., and DiTullio, G. R.: A seasonal study of dissolved cobalt in the Ross Sea, Antarctica: micronutrient behavior, absence of scavenging, and relationships with $\mathrm{Zn}, \mathrm{Cd}$, and $\mathrm{P}$, Biogeosciences, 7, 4059-4082, https://doi.org/10.5194/bg-7-40592010, 2010.

Saito, M. A., McIlvin, M. R., Moran, D. M., Goepfert, T. J., DiTullio, G. R., Post, A. F., and Lamborg, C. H.: Multiple nutrient stresses at intersecting Pacific Ocean biomes detected by protein biomarkers, Science, 345, 1173-1177, 2014.

Saito, M. A. and Moffett, J. W.: Temporal and spatial variability of cobalt in the Atlantic Ocean, Geochim. Cosmochim. Ac., 66, 1943-1953, 2002. 
Saito, M. A., Moffett, J. W., Chisholm, S. W., and Waterbury, J. B.: Cobalt limitation and uptake in Prochlorococcus, Limnol. Oceanogr., 47, 1629-1636, 2002.

Saito, M. A., Noble, A. E., Tagliabue, A., Goepfert, T. J., Lamborg, C. H., and Jenkins, W. J.: Slow-spreading submarine ridges in the South Atlantic as a significant oceanic iron source, Nat. Geosci., 6, 775-779, 2013.

Saito, M. A., Rocap, G., and Moffett, J. W.: Production of cobalt binding ligands in a Synechococcus feature at the Costa Rica Upwelling Dome, Limnol. Oceanogr., 50, 279-290, 2005.

Saito, M. A., Sigman, D., and Morel, F. M. M.: The bioinorganic chemistry of the ancient ocean: The co-evolution of Cyanobacteria and biogeochemical cycles at the Archean-Proterozoic boundary, Inorg. Chim. Acta, 356, 308-318, 2003.

Santoro, A. E., Dupont, C. L., Richter, R. A., Craig, M. T., Carini, P., McIlvin, M. R., Yang, Y., Orsi, W. D., Moran, D. M., and Saito, M. A.: Genomic and proteomic characterization of "Candidatus Nitrosopelagicus brevis": an ammonia-oxidizing archaeon from the open ocean, P. Natl. Acad. Sci. USA, 112, 1173-1178, 2015.

Shaked, Y., Xu, Y., Leblanc, K., and Morel, F. M. M.: Zinc availability and alkaline phosphatase activity in Emiliania huxleyi: Implications for Zn-P co-limitation in the ocean, Limnol. Oceanogr, 51, 299-309, 2006.

Shelley, R., Sedwick, P. N., Bibby, T. S., Cabedo-Sanz, P., Church, T. M., Johnson, R. J., Macey, A., Marsay, C. M., Sholkovitz, E. R., and Ussher, S. J.: Controls on dissolved cobalt in surface waters of the Sargasso Sea: Comparisons with iron and aluminum, Global Biogeochem. Cy., 26, GB2020, https://doi.org/10.1029/2011GB004155, 2012.

Sterner, R. W. and Elser, J. J.: Ecological Stoichiometry: The Biology of Elements from Molecules to the Biosphere, Princeton University Press, Princeton NJ, 2002.

Sunda, W. and Huntsman, S. A.: Cobalt and zinc interreplacement in marine phytoplankton: Biological and geochemical implications, Limnol. Oceanogr., 40, 1404-1417, 1995.

Sunda, W. G. and Huntsman, S. A.: Effect of Zn, Mn, and Fe on $\mathrm{Cd}$ accumulation in phytoplankton: Implications for oceanic $\mathrm{Cd}$ cycling, Limnol. Oceanogr., 45, 1501-1516, 2000.
Sunda, W. G. and Huntsman, S. A.: Interrelated influence of iron, light, and cell size on marine phytoplankton growth, Nature, 390, 391-392, 1997.

Sunda, W. G. and Huntsman, S. A.: Photoreduction of manganese oxides in seawater, Mar. Chem., 46, 133-152, 1994.

Taylor, S. R. and McLennan, S. M.: The Continental Crust: its Composition and Evolution, Blackwell Scientific Publications, Boston, 1985.

Tebo, B., Nealson, K., Emerson, S., and Jacobs, L.: Microbial meditation of $\mathrm{Mn}(\mathrm{II})$ and $\mathrm{Co}(\mathrm{II})$ precipitation at the $\mathrm{O}_{2} / \mathrm{H}_{2}$ interfaces in two anoxic fjords, Limnol. Oceanogr., 29, 1247-1258, 1984.

Twining, B. S., Nunez-Milland, D., Vogt, S., Johnson, R. S., and Sedwick, P. N.: Variations in Synechococcus cell quotas of phosphorus, sulfur, manganese, iron, nickel, and zinc within mesoscale eddies in the Sargasso Sea, Limnol. Oceanogr., 55, 492-506, 2010.

Twining, B. S., Rauschenberg, S., Morton, P. L., Ohnemus, D. C., and Lam, P. J.: Comparison of particulate trace element concentrations in the North Atlantic Ocean as determined with discrete bottle sampling and in situ pumping, Deep-Sea Res. Pt. II, 116, 273-282, 2015.

Van Mooy, B. A. S., Rocap, G., Fredricks, H. F., Evans, C. T., and Devol, A .H.: Sulfolipids dramatically decrease phosphorus demand by picocyanobacteria in oligotrophic marine environments, P. Natl. Acad. Sci. USA, 103, 8607-8612, 2006.

Vaulot, D. (Ed.): The Cell Cycle of Phytoplankton: Coupling Cell Growth to Population Growth, Springer-Verlag, Berlin, 1995.

Wojciechowski, C. L., Cardia, J. P., and Kantrowitz, E. R.: Alkaline phosphatase from the hyperthermophilic bacterium T. maritima requires cobalt for activity, Protein Sci., 11, 903-911, 2002.

Wu, J., Sunda, W., Boyle, E. A., and Karl, D. M.: Phosphate Depletion in the Western North Atlantic Ocean, Science, 289, 752-762, 2000.

Yong, S. C., Roversi, P., Lillington, J., Rodriguez, F., Krehenbrink, M., Zeldin, O. B., Garman, E. F., Lea, S. M., and Berks, B. C.: A complex iron-calcium cofactor catalyzing phosphotransfer chemistry, Science, 345, 1170-1173, 2014. 